\title{
OPINIÓN PÚBLICA Y REPRESIÓN EN YUCATÁN: $1808-1816^{1}$
}

\author{
Laura Machuca Gallegos \\ Centro de Investigaciones y Estudios Superiores en Antro- \\ pología Social-Peninsular
}

\section{PRESENTACIÓN}

Dartiendo de Inglaterra, Francia y España hacia América, 1 entre Nueva España y Río de la Plata, las dos primeras décadas del siglo XIX estuvieron marcadas por lo que Jeremy Adelman ha llamado la emergencia de una "fuerza política"

Fecha de recepción: 14 de agosto de 2015

Fecha de aceptación: 3 de febrero de 2016

${ }^{1}$ Este artículo fue redactado durante mi estancia sabática en el Centre d'Études en Sciences Sociales sur les Mondes Africains, Américains et Asiatiques (CESSMA), de la Universidad París VII, financiada por CONACYT, Programa de Estancias Sabáticas, 2014. Agradezco a Zacarías Moutoukias, mi investigador anfitrión en CEsSMA, sus acertados comentarios y críticas a este artículo, lo mismo que a Emiliano Canto, gran conocedor de historia yucateca, y a Rodrigo Patiño, por su mirada desde afuera. Este texto también se enriqueció con los comentarios de los dictaminadores anónimos, aunque toda la responsabilidad por lo escrito aquí es mía. 
mayor: la opinión pública. ${ }^{2}$ Esta fue una nueva modalidad de acción política y así lo entendieron varios contemporáneos. ${ }^{3}$ Se trata de una época en que la imprenta tuvo un papel fundamental. Tertulias, círculos de lectura, reuniones en cafés, redacción de diarios y otros impresos fueron prácticas comunes en varios lugares del mundo, al mismo tiempo que se formaban nuevas esferas y espacios públicos. ${ }^{4}$

Me parece importante hacer una distinción entre, por un lado, los "insurgentes", aquellos que se rebelaron abiertamente contra el sistema y que en general operaron en la clandestinidad, y por el otro, los grupos tolerados que actuaron a la vista de las autoridades hasta que fueron castigados, cuando se consideró que sus prácticas excedían los límites. En este caso se encontrarían los sanjuanistas, los miembros de la Sociedad Patriótica de Caracas, los estudiantes del Café de Marco y el grupo morenista mejor conocido como "jacobinos", en el caso de Buenos Aires. ${ }^{5}$

Los sanjuanistas no resultan ajenos a los yucatecos actuales (al menos a los de Mérida): los conocen por un parque y un monumento, por la iglesia de San Juan en el bullicioso barrio del mismo nombre en el centro de la ciudad, y también porque se estudian en la escuela como parte del

2 Adelman, Sovereignty and Revolution, p. 181.

3 Hocquellet, "L'invention de la modernité par la presse”, p. 164 y nota 2; véase también Morange, “Opinion publique”, pp. 181-210.

4 Fernández y Chassin, L'avènement de l'opinion publique; Guerra y Lempérière, Los espacios públicos; Guzmán Pérez (coord.), Publicistas, prensa; Piccato, "Public Sphere in Latin America”; Rojas, La escritura de la independencia y URIBE-URAN, "The Birth of a Public Sphere in Late America”.

5 Adelman, Sovereignty and Revolution, p. 209; González Bernaldo, "La Revolución Francesa” y CAÑón, "El terror jacobino”. 
programa oficial de historia. Entre sus miembros destacan los clérigos Vicente María Velázquez y Manuel Jiménez Solís (el padre "Justis"), y entre los laicos, el conocido Lorenzo de Zavala (en ese entonces estudiante del seminario), José Matías Quintana (comerciante), José Francisco Bates (escribano real), Pedro Almeida (catedrático del seminario), entre otros personajes, que mayoritariamente eran estudiantes del seminario. En julio de 1814, Zavala, Quintana y Bates fueron procesados y conducidos a la prisión de la fortaleza de San Juan de Ulúa, donde estuvieron hasta fines de 1816, acusados de lo mismo: turbadores de la tranquilidad pública. Sobre este episodio y las causas de su castigo, la mayoría de los historiadores yucatecos ha prestado poca atención y ha repetido la misma versión desde el siglo XIX.

Se pondrá énfasis en la figura de Matías Quintana, uno de los "publicistas" más significativos, por haber sido protagonista del movimiento sanjuanista y porque es quien cuenta con más testimonios escritos. No se trata de una figura menor pues es el padre de Andrés Quintana Roo (héroe de la independencia), y aunque se han estudiado poco las fuentes intelectuales de las que éste abrevaba, su padre debió haber influido grandemente en su formación. Además representa un ejemplo claro de los nuevos "escritores públicos", quienes, según la caracterización de Álvarez Barrientos, se aprovecharon de la crítica de las costumbres para expresar sus opiniones y formar la de sus lectores. ${ }^{6}$ Este papel del nuevo escritor se reforzó en 1808 por la voluntad de actuar como mediadores resueltos a cambiar el sistema monárquico.

\footnotetext{
${ }^{6}$ Álvarez Barrientos, "Écrivains, opinion publique et pouvoir politique”, p. 53.
} 
Moisés Guzmán Pérez los ha nombrado "hacedores de opinión”, más interesados en ilustrar a la gente y tener influjo social, que en obtener ganancias pecuniarias. ${ }^{7}$

Para algunos autores los sanjuanistas fueron los precursores de la independencia en la península yucateca. No llegaron a la categoría de "insurgentes" como en el centro de México, pues no organizaron ningún movimiento armado, pero se les consideró lo bastante rebeldes como para merecer un severo castigo. Parecería que no hay nada nuevo que decir sobre ellos, ya que "Los sanjuanistas de Yucatán. Manuel Jiménez Solís" (publicado en varias entregas entre 1967 y 1971), de Ignacio Rubio Mañé, es sin duda uno de los trabajos más completos, no sólo por la densa información que ofrece sino por toda su contextualización del momento histórico. A pesar de ser un clásico, se puede criticar la imagen idealizada de los sanjuanistas - que autores posteriores se encargarán de reforzar aún más - y la poca postura crítica ante las afirmaciones de Justo Sierra O’Reilly, a quien Rubio Mañé retomó tal cual insertando largos pasajes del texto Los indios de Yucatán. De tal forma que los sanjuanistas y liberales son presentados como las víctimas del momento, mientras que los simpatizantes del rey (llamados rutineros) se consideraban los malvados. La realidad, a la luz de nuevos documentos encontrados sobre todo en el Archivo General de Indias, resulta más matizada y menos antagónica.

En esa línea siguió el cronista de Mérida, Renán Irigoyen Rosado, quien retomó literalmente la visión que Justo Sierra O’Reilly e Ignacio Rubio Mañé dejaron de los sanjuanistas: "nunca organizaron una resistencia y jamás esperaron

7 Guzmán Pérez, “Hacedores de opinión”, pp. 31-60. 
represiones. La suya había sido una escuela especulativa y filosófica más que sociedad práctica y de acción, sus medios eran solamente divulgativos, sin eficacia para la defensa de sus personas". ${ }^{8}$ Como trataré de mostrar a lo largo de estas páginas, los sanjuanistas, más que especuladores y filósofos, eran hombres de acción, combativos y a la defensiva. En lo que sí tenían razón Rubio Mañé, Sierra e Irigoyen es que sus medios eran divulgativos, es decir, creían en la prensa, en la difusión de las noticias y en el peso que podía tener la formación de una opinión pública, con lo cual habría una apertura de las instituciones.

Otros análisis más recientes también ofrecen visiones matizadas, como dos publicaciones de Melchor Campos, una centrada en las formas tempranas de sociabilidad, como las reuniones, los salones, las publicaciones, y otra sobre el simbolismo de los diferentes acontecimientos sucedidos entre 1808 y $1820 .{ }^{9}$ Asimismo, se encuentra el estudio de Betty Zanolli sobre el ayuntamiento de 1812 a 1814 (dominado por el grupo de sanjuanistas) y sus acciones. ${ }^{10} \mathrm{Tam}-$ bién debo mencionar el libro de Marcela González Calderón acerca del joven Lorenzo de Zavala, antes de que dejara Mérida y saltara a la vida nacional. Resalta que ningún autor - salvo la misma González - haya referido varios hechos llevados a cabo por los sanjuanistas y que fueron

\footnotetext{
8 Sierra, Los indios de Yucatán, vol. II, p. 93; Rubio Mañé, "Los sanjuanistas de Yucatán”, Ix: 1-2, p. 141; IrigoYen, La constitución de Cádiz de 1812.

9 Campos, Sociabilidades políticas en Yucatán y "Del absolutismo regio a la monarquía constitucional”.

10 Zanolli, "La alborada del liberalismo yucateco".
} 
considerados "tumultuosos” por las autoridades. ${ }^{11}$ Quizá esta omisión fue a propósito en aras de la construcción de una historia oficial yucateca, donde esta clase de actos del grupo considerado "modelo" no tenían cabida. Solamente el historiador Jorge Mantilla ha manifestado que los sanjuanistas no sólo no eran especulativos sino que incluso podían haber llegado a sublevarse. ${ }^{12}$

En el periodo tratado, Yucatán era una capitanía general dependiente de la Nueva España, pero más ligada al espacio caribeño, en particular con La Habana. En 1814 tenía aproximadamente 500000 habitantes, de los cuales tres cuartas partes eran mayas, $10 \%$ negros y mulatos y $15 \%$ "blancos", como eran llamados los criollos y peninsulares. Se trataba de una sociedad que dependía completamente de la mano de obra indígena, ya sea por sus tributos o su trabajo en las haciendas, que crecieron desde fines del siglo xviII. ${ }^{13}$ También se desarrollaba una actividad económica importante de intercambio con Nueva Orleans y Cuba. El esquema de explotación al indio no fue puesto en duda ni siquiera por los sanjuanistas, quienes vivían insertos en él, aunque sí tuvieron mayor apertura al proclamar el derecho de los mayas a la tierra y a la educación. Lo anterior gracias en parte a la influencia del discurso ilustrado de las Sociedades de Amigos del País. ${ }^{14} \mathrm{Al}$ menos en las fuentes

\footnotetext{
11 González Calderón, El Yucatán de Zavala.

${ }^{12}$ Comunicación personal del autor. Mantilla, "El pensamiento sanjuanista".

13 Calzadilla et al., Apuntaciones, pp. 25-27.

${ }^{14}$ Agradezco a uno de los dictaminadores este comentario. Cabe mencionar que en Mérida había varios miembros de la Real Sociedad Bascongada de los Amigos del País que quizá pudieron influir, y también de
} 
consultadas no se menciona la relación entre mayas y sanjuanistas; se infiere que había cierto influjo en los pueblos, sobre todo donde había curas simpatizantes, e incluso se puede anotar como hipótesis que ellos tuvieron que ver en la supresión de las obvenciones eclesiásticas, pero es difícil saber su verdadero ascendiente. Para Justo Sierra no hay duda de ello: "y si éstos en su exasperación hubiesen apelado a las masas indígenas, que en todo caso no se habrían detenido en semejantes contemplaciones, el resultado no hubiera sido menos funesto para el país". ${ }^{15}$

DESARROLLO DE LA OPINIÓN PÚBLICA EN YUCATÁN

El 23 de abril de 1812, Matías Quintana, en una carta dirigida al Consejo de Indias para reclamar sobre un cobro indebido de su agente en España, Juan José de la Presilla, apoderado de varios vecinos indianos en esa institución, se describía:

[como] un español americano, que con su persona y bienes ha manifestado su fidelidad y su patriotismo en toda la época de nuestra gloriosa revolución, ya impugnando los papeles seductivos con que se ha pretendido corromper la fidelidad de estos habitantes, ya colectando y contribuyendo donativos para sostener la justa causa que defendemos, y por último, formando la opinión pública en la unidad y conformidad con los sentimientos de la matria $\left[\ldots . .^{16}\right.$

La Habana seguramente llegaban noticias; sobre el tema véase Torales, Expresiones de la Ilustración.

15 Sierra, Los indios de Yucatán, vol. II, p. 82.

16 AGI, $M$, vol. 3096a, "Don José Matías Quintana vecino de América”, 23 de abril 1812. 
Me parece que en este discurso se encuentran varias claves del pensamiento y acción de Quintana: “español americano", "fidelidad”, "patriotismo”, “justa causa” y, sobre todo, “opinión pública”. Describirse como español americano lo identifica con las raíces de su padre (que era de La Coruña), se manifiesta fiel y patriota hacia una Península jamás vista ni pisada; su énfasis en el ser americano implica que es el único territorio que conoce, pero nunca fuera del marco que era permitido en la Península (la matria) a la cual le era fiel. Es necesario detenerse en una frase clave de su acción, porque además es la primera vez que se le encuentra en sus escritos: formar “opinión pública”.

Como nos recuerdan Javier Fernández Sebastián y Joëlle Chassin, las primeras formulaciones del término "opinión púbica” se encuentran en un reducido número de autores franceses de la segunda mitad del siglo XviII. ${ }^{17}$ Aunque la palabra se empezó a usar en Inglaterra alrededor de la década de 1730, en España no figura hasta 1803, cuando fue registrado en el Diccionario de la Academia. ${ }^{18}$ Aunque a partir de 1808, con la invasión del emperador Napoleón Bonaparte a España, se desarrolló en Iberoamérica formalmente el término en su connotación moderna, tal como lo desarrolló Habermas: "como el resultado de un libre debate social sobre los asuntos de interés público, resultado del cual las autoridades deberían tomar en cuenta de una forma $\mathrm{u}$ otra", ${ }^{19}$ no se puede negar que antes de 1808 hubo prácticas

\footnotetext{
17 Fernández Sebastián y Chassin (coords.), L'avènement de l'opinion publique, p. 10.

18 Morange, “Opinion publique”, p. 181.

19 Fernández Sebastián y Chassin (coords.), L'avènement de l'opinion publique, p. 22.
} 
de sociabilidad (como lecturas públicas) donde ya se observa este fenómeno. Gabriel Torres Puga, por ejemplo, refiere que si bien resulta muy difícil rastrear el término semántico a fines del siglo xvıII, es posible identificar ya sus mecanismos en los procesos judiciales y en una prensa temprana. ${ }^{20}$

Como lo ha estudiado Annick Lempérière, antes de las Cortes de Cádiz, en la Nueva España el concepto "opinión" remitía más bien a los términos "estimación" o "juicio personal". Por otro lado, lo "público" era el equivalente de "pueblo" (léase la comunidad, la república, corporación, etc.), quien no emitía opiniones sino "voces". ${ }^{21}$ Voces y rumores que han sido recuperados por Arlette Farge para la Francia dieciochesca ${ }^{22}$ y, más recientemente, por Gabriel Torres Puga en su excelente libro sobre el tema para la Nueva España. ${ }^{23}$

La misma Lempérière resalta que no es un azar que los expedientes de esta segunda década del siglo XIX estén llenos de documentos impresos que fueron archivados como pruebas de las intenciones concretas de sus autores (como en el caso tratado de los sanjuanistas); el gobierno no podía evitar el uso de la imprenta por una multitud de actores ni mucho menos ignorar la opinión de los pueblos y de las

20 Torres Puga, Opinión pública y censura. Aunque para el caso yucateco se tienen noticias de la existencia de varias tertulias, no se ha encontrado en el ramo Inquisición, del AGN, una sola referencia a indagatorias acerca de lectores de libros prohibidos o de simpatizantes de la revolución francesa; quizá sea un material que se encuentra en los repositorios del archivo eclesiástico de Yucatán, el cual no se ha consultado aún.

${ }^{21}$ Lempérière, “L’Opinion publique au Mexique”, pp. 211-226.

${ }^{22}$ Farge, Dire et mal dire.

${ }^{23}$ Torres Puga, Opinión pública y censura. 
corporaciones, sin cuya adhesión su estabilidad e incluso su existencia estaban en juego. ${ }^{24}$

Un grupo de vecinos empezó a reunirse en la iglesia de San Juan para discutir asuntos cotidianos y políticos en algún momento durante la administración del capitán general Benito Pérez Valdelomar (1801-1811). A pesar de las críticas que se le han hecho al modelo de Habermas, ${ }^{25}$ en Yucatán parece adecuarse: un grupo de burgueses que deciden sobrepasar la esfera privada y usar su razón para discutir problemas comunes. ${ }^{26}$ Esta simple reunión fue tomando un tinte más político, el mismo Pérez Valdelomar ya desconfiaba de los progresos de "esta facción", pero ninguna de sus acciones durante su gobierno fue suficiente como para acusarlos de algún delito. Incluso existe una denuncia realizada por Matías Quintana, el 22 de mayo de 1810, ante el Tribunal del Santo Oficio, contra el artista Francisco Zapari, un italiano que hacía varias obras en la catedral, por sus comentarios en favor de los franceses. Quintana afirmó que no lo acusó por odio ni mala voluntad "sino estrechado de su conciencia". ${ }^{27}$ Cabe mencionar que el ambiente antifrancés llegó a su máxima expresión ese mismo año, en noviembre, cuando Gustavo Nordingh de Witt, un dinamarqués, fue enjuiciado y ejecutado, acusado de ser un agente de Napoleón. ${ }^{28}$

24 Lempérière, “L'Opinion publique au Mexique”, pp. 225-226.

25 Para América Latina véase especialmente GuERra y LEMPÉrière, Los espacios públicos, p. 9.

26 Morange, “Opinion publique”, pp. 186-187.

27 Rubio Mañé, “Las ideas políticas en Yucatán”, p. 270.

28 Para más detalles consultar Rubio Mañé, "Juan (Emilio) Gustavo Nordingh de Witt”. 
Un año después, en 1811, el alcalde de segundo voto del ayuntamiento de Mérida redactó un escrito en el cual solicitaba acabar la venta de cargos, específicamente las regidurías. Entre los firmantes que apoyaban la demanda estaba Matías Quintana. ${ }^{29}$ Justo hasta este momento, es la acción más radical que se le ha podido identificar. La primera vez que encontramos el término sanjuanista data del 14 de diciembre de 1812; el teniente de rey, Miguel Castro de Araoz, los bautizó de esa forma en un informe, después de tacharlos de facción y de logia de San Juan; escribió lo siguiente: existían "algunos timoratos o hipócritas, que siendo adictos a la facción de San Juanistas, tienen preocupado el celo del Jefe Superior de Yucatán". El nombre, que no había aparecido antes, se quedaría de este momento en adelante. ${ }^{30}$

\section{EL MOVIMIENTO SE RADICALIZA: \\ PRÁCTICAS DE LOS SANJUANISTAS}

Recopilación de firmas

Sería después de la partida del capitán general Benito Pérez Valdelomar como virrey de Nueva Granada en 1811, cuando "la facción de San Juan" aprovechó el gobierno

29 Existe un antecedente de 1809 con la misma petición, pero sólo firmada por el síndico procurador: "El gobernador síndico general de Yucatán propone los medios”, AGN, A, vol. 136, 1809. Para la petición de 1811 véase "Don Joaquín Chacón alcalde de primer voto de Mérida de Yucatán y otros 21 vecinos solicitando que el servicio de los oficios de regidores y demás concejiles será anual y por elección del pueblo”, AGI, $M$, 3096a, 18 de mayo de 1811.

30 AGN, IGE, vol. 257a, f. 309, "Carta de Miguel de Castro al rey”. 
interino del licenciado Justo Serrano (de agosto de 1811 a marzo de 1812), quien compartía cierta simpatía con el grupo. Así que recibió la primera demanda formal: introducir un diputado del común. Esta figura había podido instituirse en los ayuntamientos de España y también había hallado su lugar en algunas ciudades de la Nueva España, tales como Valladolid (Morelia), Jalapa y Oaxaca, entre otras. El diputado del común, sin afectar las funciones del síndico procurador, se encargaba de velar directamente por las necesidades de los habitantes de la ciudad. Su característica principal residía en que era elegido por los vecinos y no por el cabildo. ${ }^{31}$ Francisco Bates se dio a la tarea de recopilar firmas para apoyar su candidatura. Juntó $104 .{ }^{32}$ Justo Serrano, ante la presión del ayuntamiento, en contra, y de "la facción de San Juan", a favor, llegó a una solución conciliadora: nombró a dos apoderados del pueblo que serían intermediarios con el síndico procurador. El puesto duró lo que su gobierno, unos meses, pero era una partida ganada. Esta petición es importante porque fue la primera acción visible en la que el grupo usó ya algunas herramientas modernas de movilización, como recolección de firmas, una práctica que debió haber sorprendido a más de uno. Asimismo hay evidencias de su campaña para declarar libre el abasto de carnes (controlado por el ayuntamiento) y el establecimiento de una sociedad económica para fomentar el progreso de la agricultura, las

\footnotetext{
31 Sobre estos diputados véanse Hernando, "Las elecciones de síndico personero y diputados del común” y Rodríguez O., "La naturaleza de la representación”, pp. 16-17.

32 AGN, IV, c. 6693, exp. 020, 1812, “Correspondencia sometida al virrey Francisco Xavier Venegas del Ayuntamiento de Mérida”.
} 
artes y el comercio. ${ }^{33}$ Almeida, en Un mejicano, menciona que la primera conjuración del grupo fue el 23 de diciembre de 1811; unos la "llamaron asonada, otros acción popular y todos derecho de petición", para dar cumplimiento al decreto de las Cortes de Cádiz de 22 de abril de 1811, sobre abolición del tormento y apremios, y que tendrá su conclusión con el episodio que narraremos a continuación. ${ }^{34}$

\section{Mítines}

El brigadier Miguel de Castro y Araoz, como teniente de rey en Campeche, asumió la Capitanía General del 8 de enero hasta el 21 de marzo de 1812, mientras el gobierno político lo ejercía Justo Serrano. La relación de Castro y Araoz con los cabecillas del movimiento fue pésima y todo empezó cuando por su orden un vecino de Mérida (Lorenzo Argaiz) fue encarcelado y amagado con dos pares de grillos por unos reclamos que aquí no interesan. El punto es que Pedro Almeida, Matías Quintana, José Bates y Lorenzo de Zavala acusaron a Castro y Araoz de haber infringido la ley, ya que citaban una cédula del 30 de mayo de 1811 en que se cancelaba toda pena corporal. ${ }^{35}$ En efecto, el mismo Castro y Araoz calificó este movimiento iniciado contra él como "pequeña revolución”, aunque para Almeida

33 AGN, I, vol. 1, exp. 8, 1811, ff. 412-412v., "El ilustre ayuntamiento de Mérida sobre varias inquietudes que causan al público don Francisco Bates, don Matías Quintana y otros individuos".

${ }^{34}$ Almeida, Un mejicano, pp. 313-314.

35 AGN, IGE, vol. 257a, ff. 292, 16 de marzo de 1812, "El señor Gobernador de Campeche anuncia el mal estado e insubordinación en que se halla la provincia por influjo de Justo Serrano". 
se trató de "una conjuración”. ${ }^{36}$ Sólo se cuenta con su testimonio que escribió meses después, y me parece relevante porque alude al apoyo popular con el que ya contaba el grupo. El día 15 de marzo fue informado de "un corrillo por el pueblo” que discutía la prisión de Argaiz, y para evitar "aquellos preludios de inquietud" decidió soltar al reo, a quien en las afueras de la cárcel ya lo esperaba "una turba de sediciosos" que lo llevaron cargando por las calles de Mérida. Al parecer, Serrano intentaba aprovechar la reunión del cabildo al siguiente día para discutir sobre la conveniencia de despojar a Castro de su mando de jefe general de las armas. Pedro Escudero, un vecino de las familias más distinguidas, sondeó entre los regidores con más peso sus puntos de vista y la mayoría estaba con Castro, si bien manifestaban algún temor de sedición, "por las sospechas que ya tenían del carácter y opiniones de los agentes del orden". ${ }^{37}$

La mañana del 16 de marzo Quintana, Almeida, Bates y Zavala congregaron a unas 50 personas enfrente de las casas consistoriales para clamar que Castro fuera destituido. Los cuatro lograron que se les invitara a la sala capitular a exponer su queja, y según Castro se atrevieron a entrar en discusiones y altercados con los regidores, quienes sufrieron "con una paciencia heroica estas injurias”. En la plaza continuó

${ }^{36}$ Esta "segunda conjuración" sucedió el 14 de marzo de 1812 "para reclamar al gobernador sobre exceso de autoridad: en ésta el Ayuntamiento entonces perpetuo de esta capital, tomó parte, y por acta de 16 de dicho marzo, regularizó el acto acordando, que el pueblo presente nombrase, como nombró, cuatro individuos de su número para representar". Almeida, Un mejicano, p. 314.

37 AGN, IGE, vol. 257a, ff. 298-298v., 12 de septiembre de 1812. MACHUCA, "El cabildo de Mérida" ha analizado que éste era completamente regalista y enemigo de los cambios. 
"la turba" que se fue disipando poco a poco. "El complot se deshizo".38

Castro no pudo ponerse de acuerdo con Serrano y estuvo a punto de asumir el gobierno político, pero no lo hizo siguiendo la recomendación de varios personajes, incluido el obispo, de que lo mejor era esperar la llegada del nuevo capitán general y gobernador, quien de hecho presentó sus cartas el 23 de marzo. Para Castro, quien tomaría el poder tres años y medio después, eran

[...] dignos de mayor desprecio [...] Solamente esos cuatro revoltosos y algunos otros pocos de su devoción y sistema que quieren exaltarse a costa de la ruina de sus compatriotas, pretenden alterar al pueblo con la sagrada llama del Patriotismo, del despotismo de los jueces imprescriptibles del hombre, $\mathrm{y}$ otras expresiones favoritas que están de moda para alucinar con estos conceptos lisonjeros la sinceridad de los incautos. ${ }^{39}$

\section{Toma de calles: música y fuegos artificiales}

Desde marzo de 1812 estuvo a la cabeza del gobierno y capitanía general de Yucatán el mariscal de campo Manuel Artazo y Barral; su papel estuvo muy lejos de como nos lo pintan algunos autores. Por ejemplo, Aurea Commons apunta que "durante su administración fue muy intensa la actividad política, en la que ocupó gran parte de su tiempo; su

38 AGN, IGE, vol. 257a, ff. 299-299v. Es de notar que el galicismo complot también es un término que apenas se empezó a utilizar a principios del siglo xIX en América.

39 AGN, IGE, vol. 257a, ff. 301. Subrayado en el original. 
actuación fue muy acertada y discreta". ${ }^{40}$ Sus contemporáneos no compartieron esa opinión, pues según ellos era influenciable y no era él precisamente quien llevaba las riendas del gobierno. En una carta del cura Manuel Pacheco, miembro de la diputación provincial, al cura Pantiga, diputado en las Cortes de Cádiz, le refería lo siguiente:

Pantiga Amado. Recibí su apreciable de 16 de diciembre fecha en Cádiz que consoló mi corazón y el de su ilustrísima y amigos. ¡Gracias a Dios que aún viven nuestras esperanzas del remedio de nuestros males!; Artazo, este animal ha envuelto la provincia en mil desordenes, dirigido de [Pablo] Moreno [...] Enteramente arruinó la provincia, la religión y respeto de toda autoridad, especialmente a la del mismo jefe que se le ha entregado incauto y bestia, incapaz hasta de sacramentos. ¡Ah! ¡Si tardo el remedio, si otro jefe de carácter y de luces no aparece breve! ¡Pobre Yucatán! Toda está revuelta ya los curas abandonados de los bárbaros ingratos indios. Aquí ya refugiados ocurren al jefe y ni los oye. Mira al obispo cómo lo insulta el adjunto, sin recurso en el jefe, ni junta censoria, toda compuesta de los insurgentes, gavilla de san Juan donde ya se plantó un cisma [... $]^{41}$

Ignacio Rubio Mañé escribió el estudio más detallado sobre el gobernador y capitán general Manuel Artazo; aquí

40 Commons, Las intendencias de la Nueva España, p. 144.

${ }^{41}$ AGI, $M$, vol. 3032, núm. 7.57.2, f. 721, 14 de marzo de 1814. Manuel Artazo escogió como su secretario a Pablo Moreno, quien simpatizaba con los sanjuanistas, aunque no lo era abiertamente. Muy poco se ha trabajado a Moreno, antiguo alumno y profesor del seminario: con una mente brillante, pudo casarse con la hermana o hija de uno de los más recalcitrantes y regalistas regidores de Mérida, Miguel Bolio. José Ignacio Rubio Mañé, "Estudio Biográfico de D. Pablo Moreno", Diario de Yucatán (domingo 10 sep. 1933), núm. 2513. 
sólo esbozaré los argumentos que él no desarrolló concernientes al tema aquí tratado, no sé si por omisión intencionada o por no haber tenido acceso a los documentos. ${ }^{42} \mathrm{El}$ episodio es la Constitución de Cádiz, que fue promulgada el 19 de marzo de 1812. El diputado Miguel González Lastiri regresó a Yucatán con una copia a fines de julio de ese año y se proclamó en Mérida el 14 de octubre. ${ }^{43}$

El padre Vicente María Velázquez fue el encargado de darla a conocer en sus reuniones de la ermita de San Juan. Según Almeida, hubo una tercera conjuración el 7 de agosto para pedir al gobernador que se publicara; no ofrece más detalles. ${ }^{44} \mathrm{Al}$ mismo tiempo, por carta de 8 de agosto de 1812, 55 ciudadanos solicitaban al capitán general que se diera a conocer la Constitución. Artazo decidió pedir su parecer a varias personalidades, entre ellas a José María Origel, auditor de guerra, teniente asesor de gobierno e intendencia, el licenciado Martínez de la Pedrera, futuro diputado a Cortes, el mismo González Lastiri y al ayuntamiento de Mérida. Todos coincidieron en que publicarla no significaba que se llevarían a cabo sus artículos. ${ }^{45}$

Un testimonio de Matías Quintana nos aclara su punto de vista sobre todos estos acontecimientos; en carta de 12 de agosto de 1812 escrita a su hijo Andrés se mostraba bastante optimista:

42 Rubio MAÑ̃é, “El gobernador, capitán general e intendente de Yucatán”. 43 A la Ciudad de México, por ejemplo, llegó un ejemplar el 27 de junio y fue jurada el 30 de septiembre; en Guatemala, para citar otro caso, se juró el 24 de septiembre Agradezco atentamente este dato proporcionado por uno de los dictaminadores anónimos.

${ }^{44}$ Almeida, Un mejicano, p. 314.

${ }^{45}$ Rubio MaÑé, "El gobernador, capitán general e intendente de Yucatán”, pp. 81-82. 
Vamos a jurar la Constitución. Aquí hay la guerra que ha habido en España de Rutineros y Liberales: Tengo el honor de ser de los liberales pero por esto me llaman asceta jacobino, mentecato. Seguimos en paz y espero que con la publicación de la Constitución consolidaremos nuestra hermandad, sólo el despotismo está dando sus últimas bocanadas. Aquí sin imprenta se han publicado papeles excelentes, ahora verán que Mérida tiene talentos [...] Tenemos un gobernador muy negado: dicen que totalmente no entiende. Yo lo visito con frecuencia, tiene buenas intenciones, es religioso, pero dicen que muy ignorante y su asesor Origel ¿considera como maña esto? Yo sigo bien con el gobernador. ${ }^{46}$

Justamente el cronista Irigoyen Rosado dividió a la sociedad meridana de 1812 en tres grupos "al parecer irreconciliables”: el de los absolutistas (o rutineros), los liberales (más numerosos) y los radicales (sanjuanistas)" ${ }^{47}$ Un detalle no mencionó Rubio Mañé sobre la publicación de la Constitución y que Castro y Araoz, que ya les tenía ojeriza, no omitió aun sin haber inquirido "exactamente la realidad de estas ocurrencias”. El 23 de septiembre los sanjuanistas habrían decidido que publicarían la Constitución, sin esperar orden ni mediación de autoridad alguna. De hecho, "la pandilla” habría salido a la calle con música, fuegos y alborotos y el gobernador Artazo apenas habría podido disiparles. ${ }^{48}$ Estas “ocurrencias” no debieron estar muy lejos de la realidad porque el 25 de septiembre el obispo Agustín Estévez

${ }_{46}$ AGN, IG, OG, c. 1160, exp. 47, "Correspondencia emitida por Josef Matías Quintana”.

47 Irigoyen, La Constitución de Cádiz de 1812, pp. 29-30.

48 AGN, IGE, vol. 257a, ff. 303-304, 30 de septiembre de 1812. 
y Ugarte lanzó su edicto de excomunión, que además ratificó el 28 del mismo mes. Reproduzco una parte larga porque corrobora lo contado por Castro:

[...] teniendo informes ciertos y contando por diligencias judiciales que en la Sacristía y Casa de la Iglesia de San Juan, de cargo del Presbítero don Vicente Velásquez se juntan hasta deshora de la noche varias personas eclesiásticas y seculares, algunas conocidas por sus ánimos inquietos, otras sospechosas de formar los pasquines, calumnias y papeles infamatorios [...] divulgando máximas francesas condenadas por la Iglesia, sacadas de autores notados de ateísmo, jansenismo y libertinos [...] y habiendo la noche del veinte y tres de este el ruidoso sedicioso a pretexto de leer la Constitución que se ha de publicar, obrando contra ella, juntando mucha gente en el atrio de dicha iglesia sin licencia del Gobierno, ni consentimiento de Juez Eclesiástico, saliendo después alborotando el pueblo con fuegos, gritos y mitotes. Para apartar estos y otros temibles escándalos del pueblo cristiano, debía mandar y mandó se disuelvan y acaben dichas juntas en éste y otro cualquier sitio, pena de excomunión mayor ipso facto incurrenda [...]. ${ }^{49}$

En su análisis sobre la opinión pública en España, Claude Morange nos explica que por regla general los liberales consideraban que la opinión se podía manifestar por medio de las elecciones, de la imprenta y del derecho de petición; sólo una minoría defendía la legitimidad de las tribunas, clubes y el derecho de reunión, y un grupo más reducido aún

${ }_{49}$ AGI, $M, 3097$ a. La cédula de excomunión del 28 de septiembre también se encuentra en AGI, $M$, 3096a, "A nuestros amados fieles en Nuestro Señor Jesucristo". 
daba legitimidad a las manifestaciones de la calle. ${ }^{50}$ Resulta entonces que los sanjuanistas pertenecían a ese sector radical, partían de la idea de que expresar sus ideas en la calle estaba completamente justificado.

\section{Lecturas públicas, la Constitución}

El 28 de septiembre de 1812, 32 vecinos de Mérida dieron su poder al catedrático de Latinidad, Pedro Almeida, para que los representara en la acusación que se les imputaba de ser concurrentes a las lecciones públicas de la Constitución de Vicente María Velásquez, ya que creían su "honor vulnerado" por el auto de censura del obispo Estévez. ${ }^{51}$ El 8 de octubre Almeida manifestó en una carta que, en efecto, el 23 de septiembre se habían reunido y festejado con música y "vivas aclamaciones" la conclusión de la primera lectura de la Constitución, sin presentarse desorden alguno, y esperaban obtener permiso para continuar. Se extrañaba que después de seis meses el gobierno no se hubiera dignado publicarla, y ni siquiera manifestado algún acto de regocijo. Dice haber recibido los documentos del obispo de 25 y 28 de

50 Morange, “Opinion publique”, p. 198.

${ }^{51}$ Los que firmaron eran: Juan de Dios Henríquez, José Francisco Negroe, Jesús Vicente María Velázquez, Manuel García y Sosa, Domingo de Lara, Lorenzo Zavala, Ildefonso Montore, Joaquín Correa, Francisco Antonio del Canto, Ambrosio María Pinelo, Ignacio Marchena, José Anastasio Medina, Antonio del Valle, José Policarpo Tenorio, Juan José Espejo, Miguel de Peraza, Simón de Vargas, Lorenzo Argaiz, José Ignacio Méndez, Rafael Aguayo, Bernabé Negroe, José Peón, Alejandro Montero, Faustino Imán, Manuel Imán, Nicolás Ramírez, José Lázaro Mena, Domingo Cantón, Agustín de Zavala, Juan Esteban Rejón, Manuel de Ávila y Francisco del Castillo. AGI, $M$, vol. 3097a, ff. 8v.-9, 6 de octubre de 1812. 
septiembre, quien so pena de excomunión los conminaba a disolver la sociedad de San Juan, ya que había dado por verdaderos ciertos informes que eran sólo calumnias y así contravenía el artículo 301 de la Constitución. Por lo tanto, solicitaba que el obispo suspendiera el auto y el edicto y que se le remitieran las diligencias originales para poder recurrir a sus "calumniadores". En una posdata recomendaba que el obispo mandara una persona que estuviera presente en sus lecciones nocturnas. ${ }^{52}$

La respuesta del obispo Estévez fue contundente: "No ha lugar a este incivil recurso contrario a los cánones de la iglesia, concilio nacional y Constitución [...] No ha lugar a levantar las censuras, antes de nuevo las fulminamos también contra ellos [los 32 firmantes] como fautores y promotores". En una carta del 9 de octubre el gobernador Artazo pidió su parecer al obispo para que esta enseñanza pudiera realizarse en el seminario. ${ }^{53}$ El obispo contestó que si se trataba de leer la Constitución pues se haría en el mismísimo seminario y en las otras parroquias, cuando hubiera más ejemplares, que el rector impartiría la lección de media hora los días

52 AGI, $M$, vol. 3097a, ff. 10-12, 8 de octubre de 1812, "Carta de Pedro Almeida al obispo". El artículo 301 dice así: "Al tomar la confesión al tratado como reo, se le leerán íntegramente todos los documentos y las declaraciones de los testigos, con los nombres de estos; y si por ellos no los conociere, se le darán cuantas noticias pida para venir en conocimiento de quienes son", en Constitución política de la monarquia, consultada el 26 de enero de 2015 en http://www.cervantesvirtual.com/obra-visor/ constitucion-politica-de-la-monarquia-espanola-promulgada-en-cadiza-19-de-marzo-de-1812-precedida-de-un-discurso-preliminar-leido-enlas-cortes-al-presentar-la-comision-de-constitucion-el-proyecto-deella--0/html/000d0672-82b2-11df-acc7-002185ce6064_223.html

53 AGI, $M, 3097$ a, 23 de julio de 1814, "La Diputación Provincial informa el estado". 
lunes y jueves, a las 10 de la mañana en invierno y a las 9:30 en verano, y en caso de no poder él mismo lo remplazaría. ${ }^{54}$ Es decir, con tal de que no se entrometieran los sanjuanistas, el obispo incluso aceptó la Constitución.

No sólo existían las lecciones de Vicente María Velásquez, también José Francisco Bates pidió autorización para abrir su sala de lectura de la Constitución. La irritación del obispo ante esta demanda llegó al máximo: "No puede estar la salud del pueblo en lo que solicita, sino la inquietud, maldición y anatema [...] siempre miraré estas pretensiones en estos sujetos como capciosas, y de malísimas resultas". ${ }^{5}$

Amenazas de sublevación, toma del máximo poder local: el ayuntamiento

Por fin, el 15 de noviembre se logró que la Constitución fuera jurada. Sería el comienzo del periodo de mayor esplendor del grupo, cuando lograron el poder político gracias a que quedaron mayoría en el ayuntamiento. Este es otro de los acontecimientos que ni Sierra ni sus seguidores mencionan. En carta del 7 de diciembre de 1812, Juan José León (juez de residencia del gobernador Pérez Valdelomar) describía a Matías Quintana como "uno de los cabecillas que con sus inventivas revolucionarias tiene a algunos incautos de esta fidelísima provincia envueltos en sus máximas y muy a los bordes de la ruina”. Lo acusó junto con sus colegas de

\footnotetext{
${ }^{54}$ AGI, $M$, vol. 3097a, ff, 6 y 12v., 9 de octubre de 1812.

55 AGI, M, vol. 3097a, f. 6, 9 de octubre de 1812, "Carta del obispo Estévez al Gobernador Artazo".
} 
haber amenazado con una sublevación y que por eso fueron elegidos la mayoría de ellos a formar parte del ayuntamiento de 1813: Quintana y Bates salieron de procuradores síndicos y Zavala fue nombrado secretario. Lo llamó "el complot de San Juan”. La primera asamblea para realizar las elecciones fue justo el 15 de noviembre; nada sabemos de los hechos acaecidos en las calles ese día. ${ }^{56}$ Matías escribió al respecto: "No ha habido revolución aquí. Sucumbió la rutina y está preponderante el partido liberal en términos que ni un rutinero salió para nada. Se teme que los eclesiásticos propaguen la rutina, pero yo no lo pienso por muy extendido el espíritu público". ${ }^{57}$ Dos "complots" sucesivos (los de 23 de septiembre y 15 de noviembre) en un periodo tan corto de tiempo eran demasiado para el obispo y el capitán general. En efecto, "el espíritu público" ganaba adeptos.

\section{Creación de escuelas}

Como se ha podido comprobar, el obispo advertía ya un verdadero peligro en los sanjuanistas, no sé si más imaginario que real, pero que en los hechos concretos desató una gran virulencia de su parte. Pero esta imagen devino más negativa aún con los acontecimientos sucedidos a raíz de la supuesta desaparición del seminario y de la instalación de una escuela sanjuanista llamada la Casa de Estudios. Dedicaré apenas unas líneas a este hecho porque ya ha sido objeto de estudio, ${ }^{58}$ pero es importante porque en el ánimo

56 Rubio Mañé, “Los Sanjuanistas de Yucatán”, IX, p. 202.

57 AGN, IG, OG, c. 1160, exp. 47, 25 de enero de 1813, "Correspondencia emitida por Josef Matías Quintana”.

58 Arcila, El proceso y Machuca “El proyecto educativo en Yucatán”. 
del obispo, esta sería la gota que derramaría el vaso. Una vez que sobrevino el regreso de Fernando VII, los sanjuanistas no encontraron ningún apoyo de parte de la Iglesia, al contrario, y lo mismo pasaría del lado del gobierno civil, el capitán general les tenía completa animadversión.

Todo comenzó cuando algunos estudiantes quemaron el cepo del seminario (el lugar donde se llevaban a cabo los castigos). Al iniciar las averiguaciones, el rector del seminario fue increpado por los estudiantes, así que decidió renunciar. Fue elegido para tal puesto Francisco Pasos, párroco de la iglesia del barrio de Santiago, pero los estudiantes tampoco estuvieron de acuerdo pues querían un catedrático en el puesto. Según el obispo, Matías Quintana tomó la protección de los colegiales, al otro día éstos renunciaron a sus becas y los profesores a sus cátedras.

El ayuntamiento entonces "determinó tomar bajo su protección la enseñanza pública” abriendo una escuela alternativa, en casa del regidor Pantaleón Cantón; sería maestro de filosofía Manuel Carvajal, de sintaxis y prosodia latina el presbítero Mauricio Gutiérrez, de menores el presbítero Rafael Aguayo; de primeros rudimentos el presbítero Pablo Oreza, de gramática castellana el presbítero Manuel Jiménez, y de constitución Pablo Moreno. La diputación provincial encargó de inmediato una investigación y el parecer del obispo. ${ }^{59}$

El obispo Estévez y Ugarte manifestó que era un engaño la desaparición del seminario. Al renunciar el rector y algunos catedráticos, fueron sustituidos inmediatamente:

59 AGI, $M$, vol. 3097a, f. 15, núm. 3, 13 de mayo de 1813. 
Por lo que mira a estos sujetos con rubor, debo decir que siendo eclesiásticos favorecidos por el Seminario y por mí, no se han portado ni como clérigos, ni como súbditos, ni como ciudadanos. Ni una palabra, ni una ocasión se me han quejado de mal trato, ni pueden con verdad, sino que siempre se les ha mirado con estimación y cariño; más la ingratitud es virtud liberal. No se llegaban a pedir cosas que no se les concediese, mas desde que se agregaron al Partido Cismático y de división de su Prelado, ni para las licencias ordinarias, ni por política y reverencia se han querido presentar. $^{60}$

Asimismo se publicaron en el Alcance al Semanal de la Diputación Provincial núm. 5 las listas de los exámenes de gramática, filosofía y teología de los colegiales del Seminario Real Conciliar, y estudiantes manteístas, junto con los profesores que quedaban, llevados a cabo el 28 de julio de $1813 .^{61}$

Uno de los trabajos de Virginia Guedea sobre una conspiración en la capital de México en 1811 ilustra muy bien el modus operandi de los sanjuanistas, aunque nosotros hablaríamos más bien de "conjuración” o “complot”, según el lenguaje de los contemporáneos. ${ }^{62}$ Tanto en México como en Mérida se trata de grupos que empezaron con tertulias cuyos miembros, pertenecientes a diversos estratos económicos, estaban ligados por lazos familiares y de amistad, fundamental para poder expresarse libremente. En ambos casos aprendieron a actuar en secreto, todas sus actividades eran una sorpresa para las autoridades, la única diferencia

\footnotetext{
60 AGI, $M$, vol. 3097a, ff. 17-18, núm. 3, 14 de mayo de 1813.

${ }^{61}$ AGI, $M$, vol. 3097a, f. 14.

62 Guedea, "The Conspiracies of 1811".
} 
estribó en que hubo suficiente tolerancia para los sanjuanistas y que estos últimos no optaron por la insurgencia, como sí sucedió en el grupo de México.

\section{LAS CARTAS DE QUINTANA}

Se cuenta con varias cartas personales de Matías a su hijo Andrés Quintana Roo, que escribió entre agosto de 1812 y enero de $1813 .{ }^{63}$ En varias de ellas su principal preocupación es el matrimonio que Andrés iba a contraer con Leona Vicario, y la oposición del padre a tal hecho. Matías afirmaba haber recibido la última carta de Andrés en mayo de 1812; dos meses después partiría a Zitácuaro. Le insistía mucho para que regresara a Mérida, donde podría conseguir otra mujer, pero sobre todo porque necesitaba de su apoyo. En una carta de 17 de noviembre incluso le mencionaba que estaba seguro de que uno o ambos saldrían elegidos para diputados a Cortes de Cádiz. En realidad, quienes viajaron pertenecían a sectores moderados o muy conservadores. ${ }^{64}$ Otro tema recurrente es el de la importancia de la Constitución. En carta de 17 de octubre Matías escribía:

Yo estoy bueno con tu madre y hermanos, pero más aborrecido por los rutineros. Se publicó la Constitución el 14 de éste, pero no se plantifica porque la aborrecen hasta los que sólo mandan en gallinas. Todo este fiel pueblo que conserva su tranquilidad está decidido a favor de la Constitución pero están en contra los

${ }^{63}$ Algunas de ellas fueron publicadas por MachucA, "Cartas de un padre a su indeciso hijo". El original se encuentra en AGN, IG, OG, c. 1160, exp. 47, "Correspondencia emitida por Josef Matías Quintana". ${ }^{64}$ Véase Machuca, "Diputados yucatecos". 
señores obispos, gobernador, Origel y los demás que son enfrentados. Dios quiera que la renuncia del gobierno en plantificarla no nos envuelva en una desgracia... Todos los mandones aborrecen la Constitución, pero todos los patriotas la aman y me parece tendrán que sentir sino [sic] se ajustan a ella. Pídele a Dios porque $[$ sic $]$ me saque con bien de esta revuelta de ideas. ${ }^{65}$

Un último tema es la apreciación que Quintana tenía de la respuesta de las autoridades hacia sus acciones. Resalta antes que nada la incomprensión. Quintana creía fervientemente que actuaba conforme a derecho, por tanto, no entendía la cerrazón de las autoridades: “y mientras yo y todos los adictos a la Constitución padecemos la más grande opresión de todas las autoridades: excomuniones, bandos y llamados del gobierno son los medios con que se nos ultraja”. ${ }^{66}$ Como Gabriel Torres Puga explica en su libro, figuras como los sanjuanistas eran vistas con la mayor desconfianza simplemente porque desarrollaban "prácticas de opinión”, ${ }^{67}$ completamente desconocidas en el ámbito yucateco. No obstante, a pesar de todas las trabas, estamos ante la construcción de un espacio público tolerado por las autoridades, incipiente, ${ }^{68}$ pero necesario para que las sociabilidades políticas se desarrollaran. ${ }^{69}$

A este ambiente habría que agregar el impacto que tuvo la Constitución de Cádiz en la población de fuera de Mérida,

65 AGN, IG, OG, c. 1160, exp. 47, 17 de octubre de 1812.

66 AGN, IG, OG, c. 1160, exp. 47, 7 de noviembre de 1812.

67 Torres Puga, Opinión pública, p. 34.

68 Tal como lo muestra URIBE-URAn, “The Birth of a Public Sphere”, p. 425.

69 González Bernaldo, “La Revolución Francesa”, p. 114. 
en particular la indígena. Este tema ya ha sido analizado, pero no está de más mencionar que durante el tiempo de su vigencia, los mayas se negaron a pagar las obvenciones eclesiásticas, y mucho más importante aún fue el proceso de municipalización, ya que se formaron 156 ayuntamientos en Yucatán entre 1812 y $1814 .{ }^{70}$

\section{LOS PENDIENTES COMERCIALES}

Y ADMINISTRATIVOS DE QUINTANA

Reinaba este ambiente en Mérida cuando, al mismo tiempo y, por otro lado, el coronel Juan José de León actuaba como juez de residencia del anterior capitán general y gobernador Benito Pérez Valdelomar. De León se quejó de que Matías Quintana había vulnerado los procedimientos de su juzgado y se había negado a pagar la fianza que había dado al licenciado Justo Serrano cuando fungió como asesor interino del gobierno de Pérez. ${ }^{71}$ El lugar de publicación más cercano a Mérida era La Habana. Así, en el periódico La Cena, núm. 133, del 23 de noviembre de 1812, Matías Quintana publicó un artículo titulado "Observaciones sobre la rutina residencial”; ahí explica que Justo Serrano fue condenado a retribuir al juicio de residencia una cantidad que no correspondía a sus años de servicio, 863 pesos. Serrano alegó insolvencia así que el pago recaía inmediatamente sobre el fiador, es decir, Quintana, a quien se le ordenó sólo pagar

\footnotetext{
70 Para este tema véase Bellingeri, "El tributo de los indios"; CAstillo y Domínguez, "La Constitución de Cádiz en Yucatán"; Domínguez, Liberalismo y municipalización; GüÉMEz, Mayas, gobierno y tierras y Moreno, "Pueblos y ayuntamiento".

${ }^{71}$ AGI, $M$, vol. 3096 .
} 
y no alegar: "En esta premura ocurro a la opinión pública pidiendo y suplicando a mis compatriotas me auxilien con sus luces, a fin de combatir con la razón y las leyes, el despotismo residencial, ante quienes delato formalmente la conducta antilegal, y subversiva de los señores juez, asesor y ministriles de la residencia [...]". ${ }^{72}$

En cartas del 17 y 24 de octubre de 1812, Matías Quintana escribió a su hijo Andrés acerca de este hecho, primero le describió todo el problema, incluyendo lo que él consideraba excesos de la residencia:

De aquí, que el juez llamare este legal medio de formar la opinión, subversión, revolución y sublevación cuando él era el subversivo, el revoltoso y sublevado por haber quebrantado las leyes. Y sumamente si soy delincuente porque no aqueja aquí y no allí, cuando por la Constitución nadie puede ser juzgado fuera de su territorio. Aquí estamos en paz pero en revolución de ideas y de principios. Los rutineros están furiosos, tiran contra los liberales mortalmente, yo que recibí de Dios un corazón formado en el molde de los que sancionan la Constitución [... . ${ }^{73}$

Le solicitó además informarse sobre un recurso que el juez de residencia había entablado contra él, pues se había enterado de que la Audiencia le dio razón por el temor de un movimiento popular. ${ }^{74}$ Lo anterior nos muestra que los sanjuanistas habían logrado construir alrededor de ellos una representación tal de peligro, que incluso la Audiencia actuaba con sigilo.

\footnotetext{
72 AGI, $M$, vol. 3096a.

73 AGN, IG, OG, c. 1160, exp. 47, 24 de octubre de 1812.

74 AGN, IG, OG, c. 1160, exp. 47, 17 de octubre de 1812.
} 
Otros hechos se agregaron a la lista de reclamaciones personales de Quintana. El problema más grande que desencadenó su ira contra las autoridades fue de orden económico, ya que no se debe olvidar que era comerciante. Para explicar esto, se necesita remontarnos en el tiempo al decreto de la libertad de derechos de comercio a los puertos, de 28 de febrero de 1789. Resulta que los funcionarios de Campeche no hicieron caso y siguieron cobrando los impuestos, de tal forma que una vez organizados los comerciantes, teniendo como su representante a Matías Quintana, lograron la devolución de sus pagos y la cesación de cobros, por acuerdo de 11 de enero de 1802. En Campeche sólo se aplicó lo segundo, hasta que el 23 de febrero de 1810, la Junta Superior de Real Hacienda admitió devolver 7414 pesos que pertenecían a Quintana, más 10000 pesos a cuenta de otros $28399 .{ }^{75}$ Quintana estaba más que satisfecho con sus más de 17000 pesos y con la promesa de recuperar todo. Pero de 1810 a 1813 los tiempos cambiaron, no sólo en la Nueva España sino en la familia de Quintana. Desde marzo de 1813, Félix María Calleja había sido nombrado jefe superior político de Nueva España, y seguro no ignoraba los lazos que unían a Matías con Andrés Quintana Roo, de otra forma no se explica que el 31 de julio de 1813 ordenara a Matías restituir todo el dinero, otorgándole sólo dos días para hacerlo. El gobernador Manuel Artazo, ni tardo ni perezoso, mandó embargar a Quintana los 17414 pesos. Éste en contraataque, en cartas de 23 y 30 de octubre de ese año, exigía que se le devolvieran sus 38399 pesos. ${ }^{76}$ Con el "Manifiesto" en

\footnotetext{
75 AGI, M, 3096a, "Manifiesto", 1813.

76 AGI, M, vol. 1115, f. 447. AGI, México, 3096a, “Manifiesto”, 1813.
} 
donde hizo saber al público toda su lucha, empieza la guerra de Quintana en la prensa.

Ese mismo día, 30 de octubre, Quintana reunió al ayuntamiento de Mérida en cabildo extraordinario, donde fungía como síndico primero para quejarse de la "tropelía" de Calleja. El ayuntamiento, una vez dejado muy claro que no se ocupaba de asuntos contenciosos sino sólo de medidas económicas y de buen gobierno, se tomó la enorme atribución de pasar una nota al intendente, capitán general y jefe superior político Manuel Artazo acerca de "que un mínimo tribunal, habiendo revocado varias sentencias conformes quiera ejecutar la que la ley prohíbe". ${ }^{77}$ La causa se suspendió en el último momento y sus bienes no fueron embargados, ${ }^{78}$ pero una semana después sufrió la muerte de su hija Tomasa. En la sección de avisos de El Misceláneo había una nota de su parte, donde suplicaba "á sus amigos acompañen el cadáver". ${ }^{79}$ El Manifiesto contra Manuel Artazo y Félix María Calleja se intitula

[...] de las notorias infracciones con que los Señores capitanes generales de las provincias de Nueva España y península de Yucatán, D. Félix María Calleja y D. Manuel Artazo, insultan descaradamente a la Constitución y las leyes pisándolas y quebrantándolas, más escandalosa, y criminalmente que los rebeldes Morelos, Toledo, y demás caudillos de la insurrección, con inserción de los documentos que lo califican, para que vistos los

\footnotetext{
77 AGI, $M$, vol. 1115, 30 de octubre de 1813, ff. 486v.-487. En El Redactor Meridano del jueves 11 de noviembre de 1813, núm. 26 se encuentran publicados los acuerdos del Ayuntamiento, véase AGI, $M$, vol. 3096a. 78 AGI, $M$, vol. 1115, f. 491v., 6 de noviembre de 1813.

79 BY, El Misceláneo (13 nov. 1813), p. 4.
} 
hechos, decida el español imparcial, si esta parte de la América septentrional tiene razón para resentirse de los golpes despóticos, y arbitrarios, con que lo tiranizan sus principales mandones.

Publicado como separata, luego pasó a formar parte de Clamores de la fidelidad americana contra la opresión; de hecho el primer número salió publicado el 15 de noviembre de $1813 .^{80}$

Aquí vale la pena hacer un breve paréntesis. El ayuntamiento de Mérida se encargó de instalar la primera imprenta en 1813, traída de La Habana con dos prensas. ${ }^{81}$ Con una mayoría sanjuanista, sus miembros sabían que para influir en la opinión pública debían contar con esta poderosa herramienta. A pesar de las aportaciones de varios grupos, José Francisco Bates se comprometió a pagar los más de 7000 pesos del costo, a dos años. Sólo en 1813 se publicaron siete periódicos, siendo dos los impresores, el mismo José Bates y el santanderino José Fernández Hidalgo. ${ }^{82}$ No cabe duda de que hasta el lunes 9 de mayo de 1814, en que se dejó de imprimir, Clamores fue la gran tribuna de Quintana, la vía ideal para manifestar su inconformidad y para crear opinión pública.

ACCIONES DEL GOBERNADOR Y CAPITÁN GENERAL ARTAZO

En enero de 1814 Artazo escribió a la Regencia un largo documento contra Matías Quintana para defenderse de sus acusaciones, con una discusión que se centra en dos puntos,

80 AGI, M, vol. 3096a, “Manifiesto", 1813. La versión completa está reimpresa en facsímil, QuINTANA, Clamores.

81 González Calderón, "La imprenta”, capítulo 1.

82 González Calderón, “La imprenta”, p. 38 y cap. 2 para los impresores. 
por un lado el asunto de la deuda y por el otro un hecho que conocemos poco, la encarcelación del Ayuntamiento de Espita, un pueblo importante de Yucatán. ${ }^{83}$

En su carta Artazo manifiesta que él sólo había obedecido órdenes, hasta tal punto que incluso había aceptado la publicación de la Constitución en Yucatán. Afirma haber sido tratado siempre con toda distinción de acuerdo con sus circunstancias, hasta que encontró a Quintana, poseedor de una "voraz pluma", que al insultarlo fomentaba "la insurrección de Nueva España”, "de que es su hijo Andrés uno de los cabecillas, sin duda conservando en sus entrañas el germen de las de su padre". ${ }^{84} \mathrm{Al}$ solicitar a Quintana que devolviera el dinero que debía a la Real Hacienda, no había hecho más que obedecer las órdenes de Calleja, que en términos amplios era la figura con más poder en ese momento en Nueva España. No creía que con esta acción estuviera faltando en nada a la Constitución ni a las leyes ni por eso ser "refractario, traidor y digno del último suplicio", como lo había tachado Quintana.$^{85}$ El Ayuntamiento de Mérida, al apoyar a Quintana, no quedaba indemne. En cuanto a la deuda motivo de todo el problema, no lo solucionó "no por timidez, sino por los impulsos de justicia y obediencia a las Leyes inseparables de mi corazón”. Ni el asesor de la intendencia ni el doctor González Lastiri, regidor del ayuntamiento, los dos letrados de la intendencia, se atrevieron a dar su punto de vista. Artazo afirmaba que él sólo era el ejecutor de las decisiones de la Junta Superior de Hacienda Pública.

\footnotetext{
83 AGI, $M$, vol. 3115, ff. 444-456, 21 de enero de 1814.

${ }^{84}$ AGI, $M$, vol. 3115, f. 447.

${ }^{85}$ AGI, $M$, vol. 3115 , f. 448 v.
} 
El segundo punto por el que Quintana acusó al capitán general y gobernador es por haber encarcelado a los miembros del ayuntamiento de Espita, quienes fueron cesados al considerar que las elecciones habían estado plagadas de irregularidades. Se eligió un nuevo Ayuntamiento, pero los depuestos no lo dejaron asumir sus funciones hasta que se encarceló a los cabecillas. Artazo solicitaba que el Manifiesto de Quintana fuera examinado y se cotejaran sus afirmaciones con los hechos, lo cual comprobaría que éste merecía un castigo ejemplar:

[...] y siendo como es, contrario a éstas, falso, calumnioso y revolucionario, mandar que su autor sea castigado y caiga domado por la severa justicia de V. A. bajo el yugo de la Ley: que halle en la vergüenza de su pública retractación el abatimiento de su jactancia e insolente orgullo y en la pena condigna de su calumnia e impostura, aprenda a no atentar en lo sucesivo contra el honor de un magistrado $[\ldots]^{86}$

Si Artazo alguna vez tuvo simpatía por Quintana, después del Manifiesto su actitud cambió, y si la Regencia no actuaba en contra, él como representante del rey ausente, y máximo juez, sí podía hacerlo llegado el momento.

Ya desde septiembre de 1813, la Regencia del reino había pedido informes a Manuel Artazo "sobre una junta nocturna con el nombre de San Juan [...] calificada de facciosa y dirigida por un presbítero (que se llama don Vicente Velázquez) con otros asociados de sospechosas opiniones",

${ }_{86}$ AGI, $M$, vol. 3115, f. 452v. El proceso completo está en AGI, $M$, vol. 3096b, "Sumaria seguida por el subdelegado don José de Zepeda contra los individuos del Ayuntamiento de Espita”. 
también llamados "liberales". ${ }^{87}$ Artazo no contestó hasta las vísperas del fin del movimiento, en junio de 1814. Afirmaba que los sanjuanistas se pasaban criticando a los "adictos al sistema antiguo", sus ideas las "procuraban imprimir con especialidad en el común pueblo, con el espíritu de adquirir sus sufragios en las votaciones." Admitía que si bien la situación no era como en Cartagena o Caracas, no podía menos de tener en observancia a este grupo, a cuyas reuniones el obispo tuvo que decretar censura eclesiástica. ${ }^{88}$ Esta vez se mostró más tranquilo que en enero, porque ya corrían los rumores del regreso de Fernando VII; quizá sabía que todo era cuestión de esperar para que las cosas tomaran de nuevo su rumbo.

\section{LOS RUTINEROS TAMBIÉN SE VALEN DE LA PRENSA PARA CREAR OPINIÓN PÚBLICA}

El desarrollo de una opinión pública fue un proceso que tocó tanto a los bandos liberales como a los monárquicos, aunque creo que la tendencia de la historiografía ha sido estudiar más el papel de los primeros que el de los segundos. Sin embargo, y como ya lo ha resaltado Rafael Rojas, si en algo se caracterizan ambos, al menos en el caso mexicano, es en su fidelidad a Fernando VII y a la religión católica. ${ }^{89}$

En el periódico El Sabatino del 29 de enero de 1814 apareció un artículo que causó conmoción en Matías Quintana. ${ }^{90}$ Un tal Sigüenza le recriminaba que no hubiera

\footnotetext{
87 AGI, $M$, vol. 3006, 18 de junio de 1814, "Carta de Miguel Artazo".

88 AGI, $M$, vol. 3006, 18 de junio de 1814, "Carta de Miguel Artazo".

${ }^{89}$ Rojas, La escritura de la independencia, pp. 54-63.

90 BY, El Sabatino (sábado 29 ene. 1814), núm. 5.
} 
pagado la cantidad que Calleja le había exigido, no sólo eso sino que siguiera "desplegando los labios" contra él y el capitán general Manuel Artazo. Que Calleja había mostrado toda su fidelidad y había reorganizado todo el Seno Mexicano en la medida de lo posible, y ante cuyo nombre temblaba "ese pícaro de Morelos á quien V. en sus papeles públicos dispensa sus sufragios; agradecido de las distinciones que hace á su hijo Andrés”. Los yucatecos habían sufrido sus inquietudes e incluso habían temido sus resultados. En su Alcance a Clamores Quintana conminaba a no obedecer ni al rey, ni a las Cortes, ni ningún plan de gobierno, e igualmente había amenazado a los diputados a Cortes. Sigüenza por eso también se valía de la imprenta, "para que se sepa: que ni estamos allanados á seguir sus ideas, ni le aprobamos la comunicación que lleva con el infame Morelos, y su editor Andresillo, hijo de V”. El articulista afirmaba que la provincia de Yucatán estaba compuesta de "personas muy sensatas y religiosas" que enfrentarían como "fieras" al enemigo, "como unos verdaderos españoles"; tenían espíritu "para acabar con ellos hasta hacerlos cenisas [sic] y reducirlos á la obediencia debida á unas Constituciones tan santas, y tan sabias". Los yucatecos eran cristianos, católicos, apostólicos y romanos, y reconocían a Fernando VII. "Este es, Sr. Quintana; el camino de la Religión, y todo lo demás que debe tener por objeto un verdadero Español; y no andar con confesiones sacrílegas". Resalta que al menos cuatro veces menciona el hecho de que era sabido que su hijo Andrés andaba con "la infernal pandilla".

En realidad, la respuesta de Matías Quintana sorprende en un primer momento, ya que con el gobernador Artazo y el virrey Calleja había hecho uso de la libertad de imprenta 
para hacer denuncias y editaba Clamores para tratar de influir en la opinión pública. Matías solicitó que el texto pasara a la Junta de Censura, pues el escritor Sigüenza lo acusaba "de las mayores injurias y calumnias", como afirmar que su hijo Andrés andaba con Morelos. Lo cual a estas alturas él no podía ignorar. ${ }^{91}$ La Junta de Censura estaba integrada sólo por sus amigos y por él mismo: Vicente María Velázquez, Jaime Tintó, Manuel Jiménez, Lorenzo Zavala y Pedro Almeida. Todos consideraron en sesión de 9 de febrero que el texto era "gravemente injurioso e infamatorio" al suponer a Quintana "adicto a las ideas de los insurgentes”. Lo que procedía era que el impresor debía entregar el manuscrito y reconocer al autor, quien debía nombrar un representante para comparecer en un tribunal. El texto no admitía segunda censura. ${ }^{2}$ De esa forma el impresor José Fernández Hidalgo respondió que el responsable había

${ }^{91}$ BY, FR, Hojas sueltas, VIII-1811, 020, ff. 2-2v., "Expediente relativo a la queja de José Matías Quintana”.

${ }^{92}$ El decreto IX sobre libertad política de imprenta data del 10 de noviembre de 1813; aquí se hace referencia al decreto CCLIII, de 10 de junio de 1813, “Adiciones a la ley de libertad de Imprenta”, que en su capítulo XXVIII refería que "Quando la junta censoria de provincia, ó la suprema en su caso, declaren que un impreso no contiene sino injurias personales, el agraviado podrá seguir, según lo indica el artículo XVIII del expresado decreto de 10 de noviembre de 1810, el juicio de injurias ante el tribunal correspondiente; y por consiguiente la calificación de injurioso no puede ser reclamada, ni está sujeta á segunda censura", en Colección de los decretos y órdenes que han expedido las Cortes Generales http://www.cervantesvirtual.com/ obra-visor/coleccion-de-los-decretos-y-ordenes-que-han-expedido-lascortes-generales-y-extraordinarias-desde-24-de-febrero-de-1813-hasta14-de-setiembre-del-mismo-ano-en-que-terminaron-sus-sesiones-comprende-ademas-el-decreto-expedido-por-las-cortes-extraordinarias- $/$ html/0027cd54-82b2-11df-acc7-002185ce6064_110.html BY, FR, Hojas sueltas, VIII-1811, 020. 
sido el cura y diputado provincial Manuel Pacheco, quien como editor y redactor de la Imprenta Constitucional y del Gobierno le había dado el manuscrito

El 1ํ de marzo se presentó Manuel Pacheco al tribunal y expuso sus argumentos: 1) Que no era un secreto para nadie que Andrés Quintana andaba con los insurgentes, aunque Matías los disculpara y se dedicara a atacar a los jefes que los perseguían, tal como ya era costumbre en los Clamores, "con cuyo periódico se ha tenido una tolerancia nada decorosa a esta fidelísima provincia”. 2) Que la Junta de Censura sobrepasaba sus funciones pues no podía ser que todos sus miembros hicieran de censores, fiscales y jueces. 3) Se excedía del petitorio porque no señalaba ni las injurias ni las infamias del impreso. 4) Lo de haberlo tachado de sacrílego tampoco necesitaba prueba; era una evidencia que se dedicaba a injuriar a las autoridades y no había hecho caso a la prohibición de seguir con las reuniones de San Juan. 5) Era falso que el papel no admitiera segunda censura, pues la misma junta exponía que Quintana vertía ideas “adictas a la insurrección”. Decía que como Quintana era uno de los vocales de la Junta, había logrado que tuvieran consideración con él. ${ }^{93}$ A Pacheco además le faltó mencionar que en Clamores Quintana hizo una acérrima crítica de la Inquisición justo en el periodo en que había sido suprimida (1813-1814). Para Gabriel Torres Puga "la actitud de Quintana podría ser un indicador de que la idea de una inquisición sistemáticamente cruel e injusta comenzaba a generalizarse".${ }^{94}$ Como se puede observar, del lente de Quintana no se salvaba nadie.

93 BY, FR, Hojas sueltas, VIII-1811, 020, ff. 8-9v., 26 de febrero de 1814. 94 Torres, Los últimos años de la Inquisición, p. 139. 
El alcalde constitucional del ayuntamiento de Mérida, Basilio María Argaiz, declaró el reclamo del cura Pacheco fuera de lugar y le atribuyó "error, equivocación y más bien malición [sic]"; le conminaba a decir quién le había dado el texto, si no se le adjudicaría como suyo..$^{95}$ De ahí, el asunto de Quintana quedó olvidado e inició una guerra entre Argaiz y Pacheco. Resulta interesante hacer un esbozo porque sigue ilustrando la forma en que los sanjuanistas reaccionaron ante la crítica.

Pacheco consideró el escrito del alcalde un agravio a su persona y reclamó por el trato que se le daba. Argaiz a su vez lo acusó de "arbitrariedad, falta de respeto y despotismo", "sus expresiones tan chocantes cuanto indecorosas e irrespetuosas”. Además recordó que Quintana ya estaba habilitado a acudir a un juzgado eclesiástico a reclamar sus derechos contra el cura Pacheco, pues el texto debía entenderse como suyo. ${ }^{96}$ De nuevo Pacheco escribió una breve respuesta, y esta vez el alcalde Argaiz explotó ante las frases del cura:

[...] con una libertad propia del despotismo que tiene usted tan acreditado en la triste carrera de su vara de justicia me zahiere con el epíteto de malicioso [...] en este concepto y para no exponerme a igual desaire en que comprometa de nuevo mi sufrimiento (que no sé como hombre frágil hasta dónde alcanzará) omito entrar en más contestación a nombre del autor del Sigüenza. ${ }^{97}$

95 BY, FR, Hojas sueltas, VIII-1811, 020, ff. 10-10v., 3 de marzo de 1814. ${ }_{96}$ BY, FR, Hojas sueltas, VIII-1811, 020, ff. 13-13v., 4 de marzo de 1814. ${ }_{97}$ BY, FR, Hojas sueltas, VIII-1811, 020, f. 16-16v., 7 de marzo de 1814. Lo subrayado en el documento original. 
El 7 de marzo, por cierto, día de fiesta, hubo reunión extraordinaria de cabildo convocada por el mismo Argaiz, como alcalde primero, para reclamar por las injurias de Manuel Pacheco, sobre todo la última frase subrayada, que Argaiz consideraba una "amenaza criminal". Solicitaba al jefe político que diera cumplimiento a las leyes que tocaban al orden público y prosperidad de la provincia y de dar noticia al gobierno de las infracciones que pudieran existir; en caso de no ser así, él renunciaría. Asimismo, solicitaba al ayuntamiento ejercer estas mismas leyes que ordenaban proceder contra los eclesiásticos que denigraban al gobierno, pues si esta conducta quedaba impune habría desórdenes, además de que el público miraba ya toda esta controversia “con escándalo”. El alcalde Guzmán informaría a la Regencia sobre sus actuaciones. ${ }^{98}$

Al siguiente día, el gobernador Manuel Artazo escribió una carta al obispo donde le pedía reprender a Pacheco, quien debería actuar con mayor moderación y ser ejemplo para el pueblo en el respeto a las autoridades. Por lo tanto, lo invitaba a "disponer la conveniente satisfacción en desagravio de la autoridad ofendida". ${ }^{99}$ Pacheco se apresuró también a escribirle al obispo manifestándole que la decisión del ayuntamiento tenía más bien que ver con la "escandalosa rivalidad" con la diputación provincial, de la cual él era miembro. Pacheco estaba en lo correcto. Debe recordarse que las diputaciones eran órganos reguladores de gobierno con más facultades que los ayuntamientos y en Yucatán

${ }^{98}$ Hacía alusión al artículo 1ำ del capítulo 1ํ de la ley de 23 de junio de 1813 y a la disposición de 10 de junio del mismo año, BY, $F R$, Hojas sueltas, VIII-1811, 020, f. 14-15 y se repite en fs. 17-18.

${ }_{99}$ BY, FR, Hojas sueltas, VIII-1811, 020, f. 19 y 19v. 8 de marzo de 1814. 
funcionó al mismo tiempo que el ayuntamiento constitucional en los años 1813-1814. Solicitaba que se pidiera informe de letrados. ${ }^{100}$ La respuesta del obispo al capitán general fue la siguiente: que no estaban "en tiempo de mandarines", Artazo en andar "en papeles públicos", y que a Pacheco, "como a todos los que no son del partido, se ha procurado vilipendiar y desconceptuar con el público". ${ }^{101}$

Por esas mismas fechas, los diputados a las Cortes de Cádiz (Ángel Alonso y Pantiga, Josef Martínez de la Pedrera y José Miguel Quijano), en carta de 29 de enero de 1814 afirmaban que los sanjuanistas abusaban "de la libertad de la imprenta para formar el espíritu público", que el jefe superior político nada podía hacer por su "ineptitud", lo mismo que su auditor teniente letrado José Origel, por lo que pedían que fueran relevados de sus empleos, al menos Origel, y que el gobierno político fuera separado de la capitanía general, confiriéndose aquella primera autoridad provincial de letrado a un ciudadano instruido. ${ }^{102}$

Algunos miembros de la diputación compartían este sentir: Diego Hore, Manuel Pacheco, Francisco de Paula Villegas y José Francisco de Cicero escribieron una muy larga carta a la regencia el 23 de julio de 1814, donde narraban el desarrollo de los sanjuanistas, desde las reuniones de San Juan en tiempos del gobernador Pérez Valdelomar.

${ }^{100}$ Para el tema de la diputación véase Bock, "La dimensión simbólica"; Campos y Domínguez, La Diputación Provincial; La Diputación Provincial de Yucatán; BY, FR, Hojas sueltas, VIII-1811, 020, fs. 20-21, 8 de marzo de 1814.

101 BY, FR, Hojas sueltas, VIII-1811, 020, f. 21-22, 9 de marzo de 1814. 102 AGI, $M$, vol. 3097a, "El ayuntamiento sobre que se le faculte para consignar congrua". 
Recordaban el episodio de la encarcelación de Lorenzo Argaiz y la gran pelea con Miguel de Castro. Para ellos el capitán general Manuel Artazo era un inepto, de ahí que en lugar de controlar a los "espíritus revolucionarios", éstos tomaron alas. Reuniéndose ahora en una logia en la misma iglesia de San Juan, se decía que incluso una noche trataron materias "impías y antidogmáticas": "No sabemos la realidad de estos asertos, pero no hay duda que las discusiones tenían todo el carácter de malignas, de subversivas, y revolucionarias". Afirmaban que el gobernador no tenía la "firmeza y energía" necesarias para "estos tiempos difíciles". "El señor Artazo los aborrece, mas no los contiene," así que demandaban su remoción. ${ }^{103}$

\section{EL REGRESO DE FERNANDO VII Y LA REPRESIÓN}

Fernando VII regresó al trono el 4 de mayo de 1814; en Yucatán se supo varias semanas después. Sobre todo a partir de julio los rumores eran cada vez más fuertes hasta que se confirmó la noticia, vía La Habana. El 19 de julio los gritos en la calle a favor de Fernando VII fueron motivo de una reunión extraordinaria del ayuntamiento al siguiente día. De esa reunión del 20 de julio saldrían dos documentos, uno de parte del ayuntamiento y otro de la junta censoria, los dos firmados por Zavala, por fungir como secretario del primero y presidente de la segunda. Los regidores García Sosa, Montore y Almeida Jiménez expusieron que no obedecerían

103 "La Diputación provincial informa el estado de aquella provincia y los medios que cree más oportunos para remediar los desórdenes”, AGI, $M$, vol. 3097a, 23 de julio de 1814 . 
ningún decreto que no fuere conforme a la Constitución y mandaron publicar un bando. En el documento de la junta censoria se anotó casi lo mismo: que si el rey no juraba la Constitución no debía reconocérsele. ${ }^{104}$ El capitán general negó saber que Fernando VII hubiera abolido la Constitución y dejó que los otros se manifestaran. Con esto tuvo argumentos suficientes para justificar su actuación posterior.

Ese mismo día José Francisco Bates imprimió una proclama en donde se exhortaba a los ciudadanos a seguir observando su juramento a la Constitución, pues el regreso de Fernando VII no implicaba que ésta hubiera sido abolida. Aunque después el mismo Bates publicó otro documento donde concluía que en tiempos de la Constitución los sanjuanistas habían obedecido y que lo mismo harían con el regreso del rey. También Zavala se arrepintió públicamente de lo escrito: “¿Quién puede dejar de percibir á primera vista, que yo persuado al cumplimiento de su soberano decreto? Yo hablé de S. M. como de un príncipe ilustrado. $¿$ ¿Se pretende por ventura de que lo pinte absoluto? Esto no es conforme á su decreto". ${ }^{105}$ Ya era muy tarde.

El 22 de julio el capitán general Artazo se manifestó por medio de una publicación; ahí daba cuenta de la alegría por el regreso del rey, “a excèption de muy pocos que, ó

104 BY, $A C$, vol. 15, fs. 57-58, 20 de julio de 1814. Para más detalles véase González Calderón, "El ayuntamiento de Mérida".

105 AGI, $M$, vol. 3115, núm. 28, viernes 29 de julio de 1814. En las actas del cabildo de este día se incluyó lo siguiente: "Se recibió con la mayor satisfacción un impreso que en la mañana de este día publicó el señor Zavala retractándose de otro que dio a luz como presidente de la junta censoria, agregando verbalmente que en lo sucesivo compondría otros por fijar el espíritu público en justo homenaje de la soberanía del señor don Fernando séptimo", BY, AC, vol. 15, f. 61v., 26 de julio de 1814. 
por sus desgracias, ó por haber creido mejorar de fortuna en el nuevo orden de cosas, respiran por la prensa sentimientos contrarios, queriéndolos imprimir en los ánimos de los fieles y honrados yucatecos"; advertía que los yucatecos se habían caracterizado por su tranquilidad y los exhortaba a seguir así. ${ }^{106} \mathrm{Al}$ día siguiente un grupo de personas rompió la lápida constitucional y el 24 de julio las autoridades hicieron solemne publicación del decreto de 4 de mayo. ${ }^{107}$ Los días 24 y 27 de julio un grupo de señoras salió a la calle a destrozar constituciones y organizó una serie de celebraciones para festejar el regreso del rey. Era el triunfo de la opinión pública de la parte de los monarquistas y de la toma de la calle para manifestarse. Los rutineros habían aprendido bien la lección. ${ }^{108}$ En los próximos meses, salvo el hijo de Matías, el cura Tomás Domingo, nadie tomó su pluma para interceder a favor de los reos, quizá en una mezcla de regalismo sincero y miedo a la represión.

Justo Sierra O’Reilly afirma que el día que se rompió la lápida constitucional, también fue el del oprobio del cura Vicente Velázquez, el 24 de julio. Según los datos obtenidos por las actas de cabildo, lo primero sucedió el 23. ${ }^{109}$ Poco

106 BY, FR, 22 de julio de 1814, “El capitán general C.S.P. de la provincia de Yucatán”.

107 Esta placa existía desde 1813 y fue puesta justo por los sanjuanistas para celebrar su triunfo y el de la constitución.

108 A GI, M, 3097a, 6 de agosto de 1814, El Sabatino, Periódico instructivo. Melchor Campos resume muy bien los actos simbólicos que se realizaron en estas jornadas anticonstitucionalistas: "Del absolutismo regio a la monarquía constitucional”, pp. 133-135.

109 BY, $A C$, vol. 15, fs. 61v.-62, 26 de julio de 1814. "Como la mañana del 23 del corriente fue arrojada y reducida a fragmentos la lápida constitucional que existía en la fachada de la casa consistorial ofreció el señor 
importa el día exacto. Según su propio testimonio, pues no he encontrado otra fuente que lo corrobore, el cura fue sacado apenas vestido de su casa y paseado por las calles de la ciudad en un ridículo carruaje. ${ }^{110}$ Después sería confinado en el convento de San Francisco de Mejorada. Sobre el padre Velásquez recayeron varios cargos; uno de los testigos señalaba que el padre nunca criticó a la Iglesia, pero sí permitía que otros lo hicieran, y que cuando se mandó pagar los diezmos (en lugar de las obvenciones que los indios habían dejado de pagar), "el padre Velásquez, con los presbíteros Jiménez y Aguayo, influían a los indios de Mérida y de algunos pueblos, quantos venían para que no pagasen, siendo también el clérigo ordenante Jiménez, uno de éstos, que hablaban muy mal de todas las autoridades eclesiásticas, con el objeto de hacerlas despreciables [...]”. ${ }^{111}$ Como él, otros curas habrían sido aprehendidos; también los síndicos procuradores del Ayuntamiento, Pedro Almeida Jiménez y Manuel García Sosa, fueron encarcelados en Mérida. ${ }^{112}$ La historiografía tradicional (Sierra y después

don Pedro de Elizalde (a moción del señor capitán general jefe político) poner en su lugar y a su costa otra con el escudo de las reales armas de nuestro soberano y una inscripción a letras de oro con su augusto nombre y el de plaza real para perpetuar en la posteridad un acontecimiento tan plausible por cuya generosidad se le dieron las más expresivas gracias". 110 Sierra, Los indios de Yucatán, vol. iI, pp. 104-105; Rubio Mañé, "Los Sanjuanistas de Yucatán”, 1969, pp. 145-146.

111 “Declaración de Juan Esteban Rejón”, apud Rubio MaÑé, “Los Sanjuanistas de Yucatán”, 1969, p. 173.

112 Esto se decidió en la sesión de cabildo de 26 de julio, BY, $A C$, vol. 15, f. 60v. El mismo Pedro Almeida en su libro Un mejicano, p. 326, afirma que estuvo preso desde el mismo 26 de julio de 1814 hasta octubre de 1817: "Reo de conspiración contra un gobierno que, á pesar vuestro, debe ser eterno", p. 279. 
Rubio Mañé e Irigoyen) asevera que los tres odiados, Zavala, Bates y Quintana, estuvieron a punto de ser pasados por las armas, sin conocerse las razones por las que fueron perdonados, pero al día siguiente serían enviados a Sisal y luego a San Juan de Ulúa.

Lo que pasó esos días nos lo aclaran los propios actores gracias a las representaciones que dirigieron al rey en 1816 - con permiso del gobernador de Veracruz - suplicando que se les pusiera en libertad o que se les juzgara conforme a derecho en su territorio. Como lo aclara Ávila Quijas, una representación "era el derecho de petición”, el medio por el cual los súbditos podían solicitar a las autoridades, o al mismo rey, dar una solución a un problema específico. ${ }^{113}$ Según el testimonio de Lorenzo Zavala, el 30 de julio el capitán general Manuel Artazo lo mandó llamar con el pretexto de necesitar consultarle sobre una comisión que le había encargado la mañana del mismo día. Caído en la trampa lo encerraron en la cárcel con grillos, le hicieron prestar su declaración ante el alcalde de primer voto, Basilio María Argaiz, y a las 11 de la noche del mismo día fue trasladado al Castillo de Sisal, después a Campeche y, por último, al presidio de San Juan de Ulúa, en Veracruz. ${ }^{114}$ Sobre este hecho Bates sólo menciona haber sido apresado la tarde del 30 de julio, en la noche del mismo día haber sido conducido a Campeche, e interrogado en el mismo puerto al cabo de un mes acerca del papel que en nombre de la junta censoria

\footnotetext{
113 AGI, $M$, vol. 3097a, 1816, “Dirigiendo las tres representaciones”. ÁvILA Quijas, "La transición de la Nueva España”, p. 1462.

114 Marcela González también se ha dedicado a dilucidar qué sucedió con los sanjuanistas estos días y en particular en Zavala. Véase GonZÁlez Calderón, El Yucatán de Zavala, cap. 2.
} 
había publicado. Quintana también fue mandado llamar por el capitán general y encarcelado, conducido a Sisal y luego a Campeche. ${ }^{115}$

Por una carta de Artazo firmada el 5 de septiembre sabemos que los reos fueron remitidos a Ulúa. ${ }^{116}$ Quintana firmó su representación el 29 de agosto de 1816 y afirmaba tener 732 días de "terrible pena"; aunque no puedo asegurar que el escrito tenga la misma fecha que la firma, si hacemos la cuenta suman exactamente dos años, dos días, por lo que se puede situar su fecha de ingreso a Ulúa la primera semana de septiembre. Consta también que durante el tiempo que estuvo en Campeche tuvo tratos comerciales con José Miguel de Estrada de Campeche y con don Pedro Fernández de San Juan Bautista (Villahermosa) de Tabasco, ${ }^{117}$ lo cual indica que no estuvo totalmente incomunicado.

Antes de analizar las tres representaciones veamos la justificación del capitán general. Según Justo Sierra O’Reilly, antes del retorno de Fernando VII, Manuel Artazo se había

115 El testimonio de Zavala hace pensar que quizá él sí fue embarcado inmediatamente para Ulúa: "para extraerme de mi provincia a las diez horas de mi prisión y confinarme más de cien leguas de mi patria”, aunque quizá simplemente quiso ahorrarse mencionar su estancia en Campeche. Bates escribió que "mandó prenderme el 30 de julio y en la noche del mismo día se me condujo al puerto de Campeche, distante 40 (leguas) de mi vecindad [...] pues aunque en el citado puerto me hubieran interrogado al cabo de un mes [...]". Quintana hace constar que estuvo 57 días en prisión con grillos en Campeche, pero quizá, en realidad, sólo estuvo un mes como Bates.

116 AGN, IF, vol. 151, exp. 96, f. 443, 1814, "Expediente relativo a los reos Don José Matías Quintana, Don Lorenzo Zavala y Don Francisco Bates, remitidos de Yucatán a San Juan de Ulúa”.

117 AGEY, C, CG, vol. 2, exp. 17, 31 de agosto de 1814, "Correspondencia del gobernador Artazo". 
rodeado de gente que tuvo gran influencia sobre él; uno de ellos sería el capitán de milicias Juan Esteban Arfian, quien sería el brazo ejecutor de sus órdenes. Ciertamente la acción emprendida contra los tres sanjuanistas no fue tan repentina como se había escrito. Después de los acontecimientos del 24 de julio, el capitán general tuvo varios días para pensar qué haría con ellos; seguramente tampoco tomó la decisión solo sino aconsejado. Los testimonios nos llevan a pensar que la parte pensante en este asunto fue el asesor de intendencia y auditor de guerra, licenciado José María Origel. La decisión de mandarlos llamar y no de ir a prenderlos a sus casas, aunado a que Artazo jugó las cartas de la reconciliación hasta el último momento, explican que los tres sanjuanistas acudieran confiados a su llamado. Su acusación se centró sobre todo en el uso que dieron a su pluma "por escritores incendiarios y principales autores de los desórdenes y excesos cometidos en aquella provincia durante el sistema constitucional y de libertad de imprenta". ${ }^{118}$

El 22 de agosto de 1814, el cura Domingo Quintana, hijo de Matías, escribió una carta al rey donde explicaba claramente que la prisión de su padre no era más que una venganza del capitán general "por resentimientos personales". ${ }^{119}$ Páginas atrás se ha comprobado que los sanjuanistas eran capaces de movilizar recursos y gente para cumplir sus propósitos, pero es poco probable que prepararan una insurrección como en el centro de México, aunque los rutineros no dudaban en identificarlos como insurgentes: "cuyas ideas y

\footnotetext{
118 AGI, $M$, vol. 3006 .

119 AGI, $M$, vol. 3032, fs. 885-890, 22 de agosto de 1814, "El presbítero don Tomás Domingo Quintana”.
} 
sentimientos no distan un ápice de las de Hidalgo, Allende, Morelos y demás cabecillas de la insurrección de América ha declarado guerra abierta [...] a cuantos contribuyen de algún modo a mantener imperturbables el orden y la tranquilidad pública". ${ }^{120}$ Las autoridades vieron más peligro del que realmente había, pero esto fue suficiente para considerarlos culpables.

De las tres representaciones, sin duda la de Matías es la más larga, Zavala utilizó 10 fojas, Bates apenas 8 y Quintana 211/2. La argumentación de Bates es la más moderada; en ningún momento atribuye responsabilidad al capitán general Artazo, sino a Origel, "mi público enemigo". Escribe que su único crimen era "haber sido impresor en tiempo de la libertad de imprenta" y da múltiples ejemplos de su labor y del reconocimiento público que varias veces le había demostrado el capitán Artazo. De hecho, menciona que solicitó una copia del decreto de 4 de mayo al capitán general para reproducirla, que éste le negó. Pero cuando el hecho fue comprobado y él pudo tener en sus manos la noticia, mandó imprimirla y él mismo repartió las copias por la ciudad y los pueblos. Recalca que el día que dejó de ser procurador síndico segundo del ayuntamiento (lo fue en 1813), el capitán general elogió su labor y prometió recomendarlo al rey.

Zavala debió declarar si era el autor de los escritos del 20 de julio, uno de la Junta de Censura y otro del ayuntamiento, impresos ambos en la oficina de Bates. Zavala hace referencia al rumor que se había esparcido de que Fernando VII también había abolido el sistema constitucional y

120 AGI, $M$, vol. 3006, 14 de octubre de 1814, "Representación de Thomas O’Horan". 
de la reunión que hubo el 20 de julio con el ayuntamiento y el capitán general, en cuya presencia se emitieron los documentos, con el único objetivo de "asegurar la opinión pública en favor del gobierno establecido sujetándose como hasta entonces se había hecho al de la península española en sus últimas autoridades, aunque interinas". El capitán general pudo satisfacer "supuestos resentimientos haciendo victimas de su venganza a los que creía le habían agraviado y dar colorido de virtud patriótica a una acción en que él encontraba el triple placer de una justicia criminal". ${ }^{121}$ Zavala afirma haber sido escritor en tiempos en que la ley se lo permitía y también haber ocupado su pluma para elogiar al rey. De hecho, el 26 de julio había firmado un acta en presencia de varios testigos que quedaron satisfechos con su conducta pública. Minimiza los informes que sobre él pudieran haber hecho varias corporaciones e individuos "débiles" que daban la razón a Artazo, dado el estado de opresión que existía en la provincia. Sólo la ley de la fuerza justificaba todas las acciones de Artazo. Agradece al gobernador de Veracruz, Josef Dávila, la oportunidad de haber podido recurrir a la representación. No se clama inocente sino que solicitaba que se le siguiera su causa por la vía que el derecho prescribía en su territorio.

El escrito más explosivo es el de Quintana. ${ }^{122}$ Afirma que una hora antes de ser conducido a Veracruz fue tomada su declaración: tenía que reconocer si él había sido editor de

\footnotetext{
121 AGI, $M$, vol. 3097a, 22 de julio de 1816, "Dirigiendo las tres representaciones".

122 AGI, $M$, vol. 3097a, 29 de agosto de 1816, "Dirigiendo las tres representaciones". Aunque se observa que el escrito a una sola tinta fue redactado de una vez, la fecha está puesta con otra letra y tinta.
} 
varios periódicos que le pusieron a la vista, a lo que contestó que no sólo de esos sino de cuantos le "había permitido la ley de imprenta que entonces regía”, que recusaba al capitán general y a su auditor don José María Origel, sus "enemigos públicos”. Exige que con dictamen de letrados se determinase "si había razón para que abolida una ley fuesen juzgados por un efecto retroactivo los que habían obrado por ella, en virtud de otra posterior”. Apela a la clemencia real, insistiendo sobre los efectos negativos de la prisión: el hecho de haber estado incomunicado y con grillos, "tan terrible pena" “más dura que la muerte”. Remonta su escrito a 1808 y la actitud del entonces capitán general y gobernador, Benito Pérez Valdelomar, quien según Quintana prohibió usar unas escarapelas llamadas de Fernando VII. ${ }^{123}$ No sólo eso, en una reunión pública habría afirmado que el legítimo soberano ya era Napoleón, justificado además por la falta de libertad en la renuncia de Carlos IV. No se tiene noticia de que Pérez Valdelomar tomara ninguna medida represiva contra los sanjuanistas, por lo que la ojeriza de Quintana hacia él debe tener más bien que ver con asuntos relacionados con sus negocios comerciales. Para Quintana en las más críticas circunstancias Yucatán tuvo la infelicidad de tener por gobernantes dos hombres que "le hicieron sumir un cáliz más amargo": Pérez Valdelomar y Artazo. El primero, a sus ojos, aparece como un tirano por haber dudado de la legitimidad de la abdicación y por haber negado el uso de las escarapelas de Fernando VII cuando supo de su prisión;

${ }^{123}$ Estas escarapelas, con el retrato de Fernando VII, fueron realizadas a mediados de 1808 y al parecer estuvieron muy de moda en el atuendo personal. Véase, por ejemplo, Hernández Gutiérrez, "Las escarapelas de Fernando VII". 
el segundo habría dictado providencias dirigidas "a trastornar la tranquilidad pública”, de lo cual él como procurador síndico representó varias veces en la corte.

Al publicar su periódico, Quintana no había incurrido en el más mínimo delito, porque cuando llegó el decreto del rey hacía tres meses que lo había dejado; en sus contenidos nunca se trató contra el rey, varios de sus artículos habían sido retomados por el Diario del gobierno de La Habana, y por último en su plan con Clamores había sido justo hacer observaciones políticas sobre la conducta pública de los gobernantes, con el fin de instruir al gobierno central. Durante todo el tiempo que se imprimió ninguna autoridad lo delató, justo lo dejaron correr. En efecto, las autoridades permitieron el desarrollo de este nuevo espacio de sociabilidad.

Quintana también agradece la oportunidad que el gobernador de Veracruz les daba para manifestarse. La falta de un juicio y el haberse saltado todas las leyes sólo era obra del "implacable odio" del capitán general Artazo, que le acusaba de delincuente. En la ausencia del rey, mientras en todas las provincias había movimientos y provocaciones, Yucatán permaneció "adicta” y fiel a las órdenes de la metrópoli. Aquí Quintana hace gala de todo su razonamiento; la obediencia de los yucatecos a las determinaciones de gobierno, que si bien era interino se le suponía representante del rey, dio motivo a que fuesen llamados "adictos" a la Constitución; ellos fueron los primeros en celebrar la entrada de Fernando VII a España. Para Quintana el capitán general Artazo "sólo siguió el impulso de su violenta pasión, sirviendo de herramienta a varios individuos que le rodeaban y de que regularmente sólo era el débil eco". Según nuestro 
autor, la adhesión a la Constitución no significaba ir contra la voluntad soberana, como suponía Artazo. Quintana verá como una de las principales causas de su "desgracia", el hecho de que Artazo hubiera negado la existencia del decreto del 4 de mayo, y atribuía su prisión a los acontecimientos de los últimos días, desde que se reunió el cabildo en sesión extraordinaria el 20 de julio. Ya se ha visto que, en realidad, esto sólo fue uno más - y el último - de una serie de acontecimientos que se sumaron a su causa.

Matías Quintana afirmaba haber mostrado en múltiples ocasiones su adhesión al rey. En 1809 había dedicado un acto de matemáticas que había defendido uno de sus hijos (Andrés), con un elogio de las virtudes del rey, que se imprimió en el Diario de México. En el número del 28 de marzo de 1814 de Clamores había publicado un elogio al rey, que había sido premiado por la Universidad de México. A esto habría que agregar sus cargos en el ayuntamiento y los donativos hechos a la causa del rey. Según Quintana, el capitán general interino Castro y Araoz había decretado que se le sacara de la cárcel el 10 de septiembre de 1815, pero sólo fue un acto político y público que al final no fue comunicado al gobernador de Veracruz. Un último aspecto resalta de la representación: menciona que, según pública voz, la insurrección en Nueva España era de criollos contra europeos, pero de ser así hasta la discordia se hubiera instalado en su propia familia, compuesta por ambos grupos al estar una hija y una hermana casadas con españoles; por eso hizo saber su inclinación al gobierno de la metrópoli. Había abjurado de la Constitución y eso era lo importante.

Después de leer las representaciones queda la sensación de que los tres sanjuanistas atribuían su encarcelamiento 
principalmente a sus acciones del 20 de julio, cuando en realidad esto sólo fue el pretexto de Artazo para vengarse de ellos, ya que lo habían puesto en jaque desde su llegada a la Península. Otros de sus seguidores también fueron castigados. A Justo Serrano, por ejemplo, se le privó del ejercicio de la abogacía por el término de seis años y se le desterró de Yucatán, aunque después fue perdonado. ${ }^{124}$ Menos conocido es el proceso de represión en otros poblados; se sabe que en Valladolid al menos los reputados de más "liberales", Mateo Moreno y José Esperón, miembros que habían sido del ayuntamiento constitucional, sufrieron cárcel varios años. ${ }^{125}$

De hecho, el capitán Artazo guardó el mayor sigilo y no informó al Consejo hasta el 31 de octubre de 1814. No encontré el documento, pero por una respuesta del mismo Consejo se sabe que acriminaba fuertemente la conducta de los tres reos y pedía que, en caso de indultarles la vida, no se les permitiera volver a Yucatán como precaución política, pues su objetivo era "ejecutar una conmoción y echar por tierra el trono, el tabernáculo y el altar”. Justo del contenido de esta carta debió surgir la anécdota de que el día que los tres sanjuanistas fueron encarcelados estuvieron a punto de ser pasados por las armas, hecho que no se sustenta. ${ }^{126}$

Otro informe de la situación en Yucatán sería remitido de las oficinas de Palacio en Madrid al Consejo de Indias el 9 julio de 1815. La resolución emitida en octubre de ese año e influenciada por documentos enviados por el

\footnotetext{
${ }^{124}$ AGI, $M$, vol. 3033, núm. 93, 29 de noviembre de 1815.

${ }^{125}$ AGI, $M$, vol. 3097.

126 AGI, $M$, vol. 3006, "En cumplimiento de la real orden”, 20 de septiembre de 1816.
} 
Ayuntamiento de Campeche y por los exdiputados a las Cortes se redujo por el momento a recomendar que el capitán general fuera transferido a otro destino, que se separara de su cargo al secretario personal, Pablo Moreno, y que se cuidara que no se realizaran juntas subversivas, pero sobre los tres reos no se menciona nada. ${ }^{127}$ Artazo había muerto el 30 de agosto de 1815, y su cargo ya había sido ocupado días antes por el teniente de rey, Miguel Castro y Araoz.

El Consejo no actuó sino hasta 1816, cuando recibió las representaciones. Su resolución data del 20 de septiembre. ${ }^{128}$ Puesto que los tres reos se habían retractado públicamente de su conducta - y si ésta no era sincera, era un ámbito que no les incumbía-, no habían dado motivo de preocupación, y por la real clemencia se les ponía en libertad, se les devolvían todos sus bienes embargados o secuestrados y se les permitía volver a su casa o donde quisieran. El Consejo concordaba en que la causa fue formada únicamente por el capitán general Artazo y su auditor José María Origel, con la sola declaración de que nuestros personajes habían sido autores y editores de papeles subversivos. Nada más podía concluirse de los autos, por más que el gobernador haya tratado de argumentar que la tranquilidad pública de la provincia peligraba. Artazo resultó ser el más criticado. El Consejo admitía que su actuación fue un abuso de poder, incluso arbitraria e injusta, sólo justificable por haber sido tomada como medida en tiempos críticos y de cambios. Era incomprensible que Artazo no hubiera enviado la causa a un juez, a quien en última instancia le tocaba decidir.

127 AGI, $M$, vol. 3006, 18 de octubre de 1815.

128 AGI, $M$, vol. 3006, “En cumplimiento de la real orden”, 20 de septiembre de 1816. 
Que bien conoce el Consejo que dichos Quintana, Zavala y Bates han sido de los más exaltados sectarios de las doctrinas perniciosas e inmorales que se difundieron con el sistema establecido por las Cortes: que sus mismos impresos demuestran esta verdad y la convencen los impresos e informes agre$\operatorname{gados}[\ldots]$.

Sin embargo, el Consejo reconoce que en el fondo "no se trata de hechos sino de opiniones”. Otros en igual caso ya estaban disfrutando de la gracia del rey, y dado el estado de disidencia y fermentación en que se hallaban los dominios americanos, era muy peligroso ponerse a procesar a la gente acusada de causar desórdenes. Como llevaban dos años de confinación, sin comunicación ni auxilio de sus casas, siendo el castigo suficiente, los declaró libres. ${ }^{129}$ Debieron regresar a Mérida a fines de 1816 o principios de 1817.

Marcela González ha investigado cómo pudo ser la vida de los reos en Ulúa; a partir de testimonios de la época infiere que, a pesar de que ni la comida ni las condiciones higiénicas eran muy buenas, al ser reos de Estado tenían ciertos privilegios. Zavala en estas cárceles reforzó sus conocimientos de inglés y medicina. ${ }^{130}$ Quintana siguió dedicándose a escribir y a sus negocios. De hecho, hay testimonios que indican que de ninguna forma estuvieron incomunicados ni con grillos. ${ }^{131}$

129 AGI, $M$, vol. 3006, 20 de septiembre de 1816, "En cumplimiento de la real orden”.

130 González Calderón, El Yucatán de Zavala, cap. 2.

131 En al menos dos cartas de Artazo dirigidas al gobernador de Veracruz se hace referencia a esto, en una se disculpaba de que Quintana lo hubiera distraído de sus ocupaciones, pero siendo "tan amigo de escribir y de embrollar” le advertía que ya no siguiera dándole oídos pues si no lo 
El levantamiento de Rafael Riego en España ayudó a que Fernando VII volviera a sancionar la Constitución el 10 de marzo de 1820. Varios cambios de 1812 a 1814 se volvieron a instituir, por ejemplo, fue el fin del sistema venal en los ayuntamientos y fue restituida la libertad de imprenta. ${ }^{132}$ A propósito el último gobernador de Yucatán, Juan María Echeverrí, en agosto de 1820 informaba sobre Quintana y su grupo: que la extinguida Confederación (donde se habían integrado los antiguos sanjuanistas) había recibido una imprenta que se usaba para chismes y quejas. ${ }^{133}$

Un periódico sólo de dicha imprenta, manejado por un hombre que en la época pasada con sus escritos no perdonó medio

llenaría de solicitudes "con que acaso comprometa sus responsabilidades". En otra carta del 8 de diciembre de 1814 dirigida a Juan Nepomuceno de Échanove, Quintana ordenaba al coronel Francisco Heredia dar 50 pesos mensuales a su esposa María Ana a partir del $1^{\circ}$ de febrero, y ese dinero debía tomarlo de 1600 pesos que le había dado a su yerno Francisco Calero y que no los había cargado en su cuenta. Artazo de inmediato se dirigió al gobernador interino de Tabasco para que esos 1600 pesos ingresaran a las cajas reales a cuenta de la deuda que tenía Quintana con la Real Hacienda. Véase AGEY, C, CG, vol. 2, exp. 19, f. 6, 14 de noviembre de 1814 y vol. 2, exp. 2, f. 35, 24 de diciembre de 1814, "Correspondencia del gobernador Artazo” y AGEY, C, CG, vol. 2, exp. 19, f. 7v., 28 de diciembre de 1814.

132 Agradezco a uno de los dictaminadores anónimos esta precisión sobre el levantamiento de Riego.

133 A partir de septiembre de 1820 se empezó a reunir la Confederación patriótica en donde confluyeron antiguos sanjuanistas y algunos rutineros; a la cabeza estaba Lorenzo de Zavala y su órgano de difusión, llamado El Aristarco Universal; uno de sus objetivos era "proteger la Constitución e ilustrar a los ciudadanos en sus deberes" mediante impresos útiles. Rápidamente el jefe político la tachó de junta clandestina. Para más detalles de la Confederación véase González Calderón, El Yucatán de Zavala, pp. 95-104 y FerRer, "La coyuntura”, pp. 365-368. 
para indisponer a los europeos con los americanos, inflamado por un hijo que tiene en México entre los disidentes, hubiera bastado para trastornar la opinión pública a no haberse opuesto el de la $1^{\mathrm{a}}$ imprenta que manejado por hombres celosos del orden y de otro mérito sin más aspiración que el bien, habían al fin de neutralizar en gran parte los influjos del primero. Sin embargo, siendo su objeto ridiculizar y destruir al gobierno estando siempre el pueblo tan dispuesto a creer cuanto se diga contra éste, es menester confesar que dicho escritor ha conseguido destruir la mayor parte de aquella fuerza moral con que yo podía apoyar mi mando [...]. ${ }^{134}$

Sólo Bates se quedó en Yucatán, aunque ya no en Mérida sino en un pequeño pueblo (Baca). Zavala se fue de diputado a las Cortes en 1820 y ya no regresó y lo mismo pasó con Quintana cuando fue nombrado diputado por Yucatán en la Ciudad de México y ahí permaneció hasta su muerte el 30 de marzo de 1841. Una necrología se publicó en El Siglo Diez y Nueve de Yucatán por tal motivo; el editor recordaba "a aquel venerable anciano repetir con semblante alegre y regocijado: ¡Yucatán es libre! Iré consolado al sepulcro, con la idea de que mi patria será feliz”. ${ }^{135}$

\section{CONCLUSIONES}

¿Cómo un escribano real, un comerciante y un estudiante del seminario llegaron a ser los personajes más peligrosos de

134 AGI, $M$, vol. 3032, fs. 973-973v., 18 de agosto de 1821, "El jefe político de Yucatán: noticia”.

135 BY, El Siglo XIX (viernes 28 mayo 1841), t. I, núm. 49, p. 4. Agradezco a Emiliano Canto que compartiera conmigo esta referencia. 
Yucatán de la segunda década del siglo xix? ¿Cómo se les atribuyó tal poder y la capacidad incluso de organizar una insurrección? Como he mostrado en las páginas precedentes, por una parte, se debe a los acontecimientos que a partir de 1808 sacudieron al mundo hispánico, por la otra, al deseo de participar en las nuevas prácticas de sociabilidad que se desarrollaban en las principales ciudades. Pero también fue determinante, como pudo comprobarse en el caso de Matías Quintana, una trayectoria personal y profesional sin cuyo conocimiento no se entienden bien las decisiones que toman los actores sociales en un momento determinado de su vida.

En octubre de 1812 Quintana escribió a su hijo Andrés: "Aquí estamos en paz pero en revolución de ideas y de principios". ${ }^{136}$ Si hay una característica del periodo de independencia en Yucatán es justamente que no hubo movimiento armado, sino debates sobre la forma de ver el mundo, la ley, el gobierno justo e ideal, los conceptos y la práctica política. Los tres sanjuanistas esperaban hacer cambiar las ideas, pero su pensamiento, más acorde a los nuevos tiempos, chocaba y era considerado peligroso en un ambiente donde el regalismo y el institucionalismo reinaban. Por eso Zavala debió sentirse liberado cuando acudió a España a las Cortes de Cádiz, donde encontró a varios personajes que compartían su misma perspectiva.

Queda aún la pregunta de si realmente planeaban una insurrección. Después de la anterior revisión creo que si alguna vez cruzó por sus mentes, sabían que llevarlo a la práctica no hubiera sido factible. No era lo mismo movilizar a unas decenas para un mitin, u organizar un "complot"

136 AGN, IG, OG, c. 1160, exp. 47, 24 de octubre de 1812. 
muy localizado, que impulsar y mantener a cientos o miles para una rebelión. Quizá en Matías Quintana o en Lorenzo de Zavala alguna vez la idea pasó por sus mentes como una estrella fugaz y, aunque se radicalizaron, su regalismo pesaba más. No obstante, la idea de insurrección sí fue evocada por otros. Un testigo de la época afirmaba que él y otros miembros de la diputación provincial

[...] tuvieron que resistir con la autoridad que la Constitución daba a esta junta o cuerpo primero un partido conocidamente revolucionario que causó tantos cuidados, que produjo tantos disgustos y que por una gracia de la divina providencia, llegando en lo más crítico de las circunstancias el para siempre grande y memorable decreto de V.M. de 4 de mayo del año pasado, salvó la provincia más fiel y pacífica de la América de haberse envuelto en los desórdenes que lloramos de otros puntos. ${ }^{137}$

Es decir, las autoridades temían que "algo" podía pasar.

Yucatán no conoció movimiento armado en esta época, pues para la élite "blanca” era más importante pactar y seguir gozando de sus privilegios, que pelear. La población maya fue dejada al margen y fue fraguando sus propias luchas, que salieron a la luz durante el siglo XIX. No se necesitaron líderes “blancos” para que Yucatán viviera la guerra de castas. Para el momento histórico que tratamos, si en algo coincidían los liberales y los conservadores es que los mayas constituían la principal riqueza, y como tal valía la pena conservarlos (si bien diferían en aspectos como el acceso a la educación y a la tierra). No es casual que por la

137 AGI, $M$, vol. 3097a, 1815. “El gobernador y capitán general Castro y Araoz dirige una instancia de don Ignacio Basilio Rivas”. 
misma época la mayoría de ellos (incluido Quintana) poseyera haciendas con mano de obra adeudada.

En 1816, el Consejo de Indias resumió muy bien el meollo de los sanjuanistas y la sociedad que los criticaba: no se trataba "de hechos sino de opiniones", es decir, construyeron toda una imagen de ellos al desarrollar, en su máxima expresión, las nuevas formas de sociabilidad, de las que ciertamente participaron pocos. Ir de casa en casa para recopilar firmas, las manifestaciones públicas con música, la toma de calles, la creación de una escuela moderna, el reparto de boletines y las salas de lecturas eran prácticas desconocidas en el ámbito yucateco y fueron vistas con mucha desconfianza por las autoridades, quienes simplemente no entendieron que formaban parte del advenimiento de un nuevo estado de cosas. Unas cuantas cifras pueden resultar significativas de que estas nuevas formas de sociabilidad no ganaron terreno por el momento: hubo 104 firmas apoyando la candidatura de Bates como diputado del común, unas 50 personas se unieron para pedir la libertad de Argaiz y otras 55 se organizaron para la jura de la Constitución; después sólo 32 personas firmaron para solicitar al obispo que se retractara de la excomunión. Quizá sus simpatizantes fueron disminuyendo poco a poco, hasta tal punto que al final sólo quedarían ellos tres sosteniendo el movimiento, con otros tantos que se cuentan con los dedos de la mano, pues el miedo a la represión fue creciendo.

Aunque la guerra con fusiles no llegó propiamente a Yucatán en la época de las independencias, el uso de los nuevos conceptos y la palabra como arma para influir en la opinión pública fueron más que conocidos. Una nueva cultura política se desarrollaba, por lo que la Península, lejos de ser 
periférica, estuvo a la altura de cualquier ciudad del mundo donde se discutían los mismos problemas. ${ }^{138}$

\section{SIGLAS Y REFERENCIAS}

AGEY Archivo General del Estado de Yucatán, México.

AGEY, C, CG Archivo General del Estado de Yucatán, Colonial, Correspondencia de los gobernadores

AGI Archivo General de Indias, Sevilla, España.

AGI, M Archivo General de Indias, ramo México.

AGN, Archivo General de la Nación, México.

AGN, $A$ Archivo General de la Nación, ramo Ayuntamientos

AGN, IF Archivo General de la Nación, ramo, Infidencias

AGN, $I$ Archivo General de la Nación, ramo, Intendencias

AGN, IG, OP Archivo General de la Nación, ramo, Indiferente General, Operaciones de Guerra

AGN, IGE Archivo General de la Nación, ramo, Indiferente de Guerra

AGN, IV Archivo General de la Nación, ramo, Indiferente Virreinal

BY Biblioteca Yucatanense, Mérida, Yucatán, México

BY, AC Biblioteca Yucatanense, Actas de Cabildo

BY, FR Biblioteca Yucatanense, Fondo Reservado

Adelman, Jeremy

Sovereignity and Revolution in the Iberian Atlantic, Princeton, Priceton University Press, 2006.

Aguirre, Rodolfo

Espacios de saber, espacios de poder. Iglesia, universidades $y$ colegios en Hispanoamérica siglos XVI-XIX, México, Instituto

138 Piccato afirma que usar la esfera pública como un referente teórico en los estudios sobre América Latina es fundamental ya que "hará avanzar la alianza entre la investigación 'pequeña', de política local y lenguajes, privacidad y cuerpos, con la 'gran' escala de la investigación sobre el nacionalismo y la representación”, Piccato, "Public Sphere in Latin America”. 
de Investigaciones sobre la Universidad y la Educación-Bonilla Artigas Editores, Iberoamericana Vervuet, 2013.

Almeida Jiménez, Pedro

Un Mejicano: el pecado de Adán. Doce jornadas en doce cantos, con notas alusivas a los sucesos de la independencia mejicana en general, y relativamente a esta peninsula de $Y u$ catán, estudio introductorio de Rubén Reyes Ramírez, México, Instituto de Cultura de Yucatán, Consejo Nacional Para la Cultura y las Artes, 2010.

Álvarez Barrientos, Joaquín

"Écrivains, opinion publique et pouvoir politique en Espagne au xvinie siècle", en Fernández Sebastián y Chassin (coords.), 2004, pp. 51-68.

Archer, Christon

The Birth of Modern Mexico, 1780-1824, Washington, Rowman \& Littlefield, 2007.

Arcila Flores, Ramiro Leonel

El proceso fundacional de la Universidad Literaria, 17671824, Mérida, Yuc., Universidad Autónoma de Yucatán, 2008.

Ávila Quijas, Aquiles Omar

"La transición de la Nueva España al México republicano desde el concepto representación, 1750-1850", en Historia Mexicana, Lx:3 (239) (ene.-mar. 2011), pp. 1453-1489.

Baños Ramírez, Othón

Sociedad y estructura agraria y estado en Yucatán, Mérida, Yuc., Universidad Autónoma de Yucatán, 1990.

Bellingeri, Marco

"El tributo de los indios y el estado de los criollos: Las obvenciones eclesiásticas en Yucatán en el siglo XIX”, en BAÑos RAMíREZ, 1990, pp. 3-17. 
Bock, Ulrike

"La dimensión simbólica de los actos institucionales. La Diputación Provincial de Yucatán, 1813-1824”, en Quezada y ORTIZ YAM (coords.), 2008, pp. 83-116.

Calzadilla et al.

Apuntaciones para la estadística de la Provincia de Yucatán, Mérida, Yuc., Ediciones del Gobierno del Estado, 1977.

Campos García, Melchor

"Del absolutismo regio a la monarquía constitucional. Destrucción ritual de soberanos y crisis del estoicismo político en Yucatán (1808-1820)", en Serrano Ortega (coord.), 2014, pp. 107-158.

Sociabilidades politicas en Yucatán. Un estudio sobre los espacios públicos, 1780-1834, Mérida, Yuc., Universidad Autónoma de Yucatán, Conacyt, 2003.

Campos García, Melchor y Roger Domínguez Zaldívar

La Diputación Provincial en Yucatán, 1812-1823. Entre la iniciativa individual y la acción del gobierno, Mérida, Yuc., Ediciones de la Universidad Autónoma de Yucatán, 2007.

CAÑón VoIrin, Lisandro

"El terror jacobino en el imaginario de los intelectuales de la Revolución de Mayo", en Sanmartín Barros, Calvo GonZÁleZ y ReY TRISTÁN, 2012, pp. 195-208.

Castillo Canché, Jorge Isidro y Roger Alonso Domínguez Zaldívar “La Constitución de Cádiz en Yucatán 1812-1814”, tesis de licenciatura en antropología, Mérida, Yuc., Universidad Autónoma de Yucatán. 1986.

\section{Colección}

Colección de los decretos y órdenes que ban expedido las Cortes Generales y Extraordinarias desde 24 de febrero de 1813 
hasta 14 de septiembre del mismo año. http://www.cervantesvirtual.com

Commons, Aurea

Las intendencias de la Nueva España, México, Universidad Nacional Autónoma de México, 1993.

\section{La Diputación}

La Diputación Provincial de Yucatán. Actas de sesiones, 1813-1814, 1820-1821, introducción de Cecilia Zuleta, Rosario Lima et al. (transcripción), México, Instituto de Investigaciones Dr. José María Luis Mora, 2006.

Domínguez Zaldívar, Roger

Liberalismo y municipalización. Las reformas liberales españolas en Yucatán, 1812-1822, Mérida, Yuc., Universidad Autónoma de Yucatán, Consejo Nacional de Ciencia y Tecnología, 2004.

Farge, Arlette

Dire et mal dire. L'Opinion publique an XVIIIe siècle. París, Seuil, 1992.

Fernández Sebastián, Javier y Joëlle Chassin (coords.)

L'avènement de l'opinion publique. Europe et Amérique, XVIII-XIX siècles, París, L'Harmattan, 2004.

Ferrer MuÑoz, Manuel

"La coyuntura de la independencia en Yucatán, 1810-1821", en Ibarra (coord.), 2004, pp. 343-394.

González Bernaldo, Pilar

"La Revolución Francesa y la emergencia de nuevas prácticas de la política: la irrupción de la sociabilidad política en el Río de la Plata revolucionario, 1810-1815”, en Krebs y GazMURI, 1990, pp. 111-135. 
González Calderón, Marcela

"El ayuntamiento de Mérida en tiempos de Lorenzo de $\mathrm{Za}$ vala, 1812-1814”, en Machuca Gallegos (coord.), 2014, pp. 281-307.

"La imprenta en la península de Yucatán en el siglo XIX", tesis de doctorado, Mérida, Centro de Investigaciones y Estudios Superiores en Antropología Social-Peninsular, 2014.

El Yucatán de Zavala: sus primeros años, Toluca, Estado de México, Fondo Editorial Mexiquense, 2012.

Guedea, Virginia

"The Conspiracies of 1811: How the Criollos Learned to Organize in Secret", en Archer, 2007, pp. 85-105.

GüÉmez Pineda, Arturo

Mayas, gobierno y tierras frente a la acometida liberal en $\mathrm{Yu}$ catán. 1812-1847, México, El Colegio de Michoacán, Universidad Autónoma de Yucatán, 2005.

Guerra, François-Xavier y Annick Lempérière (coords).

Los espacios públicos en Iberoamérica. Ambigüedades y problemas, siglo XVIII-XIX, México, Centro Francés de Estudios Mexicanos y Centroamericanos, Fondo de Cultura Económica, 1998.

Guzmán Pérez, Moisés

"Hacedores de opinión: impresores y editores de la independencia de México, 1808-121", en Anuario. Historia regional y de las fronteras, 12 (sep. 2007), pp. 31-60.

Guzmán Pérez, Moisés (ed.)

Publicistas, prensa y publicidad en la independencia de Hispanoamérica, Morelia, Mich., Universidad Michoacana de San Nicolás de Hidalgo, 2011.

Hernández Gutiérrez, A. Sebastián

"Las escarapelas de Fernando VII en Canarias. 1808-1812", Las Palmas de Gran Canaria, Cabildo Insular de Gran Ca- 
naria, 1990, pp. 1392-1401 (IX Coloquio de historia canarioamericana). Consultado el 25 de mayo de 2015 en http://mdc. ulpgc.es/cdm/ref/collection/coloquios/id/829

Hernando Serra, María Pilar

"Las elecciones de síndico personero y diputados del común en la ciudad de Valencia a principios del siglo xIx", en Saitabi, 51-52 (2001/2002), pp. 401-432.

Hocquellet, Richard

"L'invention de la modernité par la presse. La constitution de l'opinion publique en Espagne au début de la Guerre d'Independence", en Fernández Sebastián y Chassin (coords.), 2004, pp. 163-180.

Ibarra, Ana Carolina (coord.)

La independencia en el sur de México, prólogo de Ernesto de la Torre Villar, México, Universidad Nacional Autónoma de México, 2004.

Irigoyen Rosado, Renán

La constitución de Cádiz de 1812 y los Sanjuanistas de Mérida, Mérida, Yuc., Ediciones del Ayuntamiento de Mérida, 1980.

Krebs, Ricardo y Christian Gazmuri (coords.)

La Revolución Francesa y Chile, Santiago, Editorial Universitaria, 1990.

Lempérière, Annick

"L'Opinion publique au Mexique: le concept et ses usages (1 $1^{\text {er }}$ moitié du xixe siècle)", en Fernández Sebastián y Chassin (coords.), 2004, pp. 211-226.

Machuca Gallegos, Laura

"Cartas de un padre a su indeciso hijo y de un suegro a su mentecata nuera. De Matías Quintana a Andrés Quintana Roo y a Leona Vicario", en Bicentenario, 11 (2011), pp. 70-75. 
"Diputados yucatecos y campechanos en Cádiz y su idea sobre la península de Yucatán, 1810-1814”, en Anuario de Estudios Hispanoamericanos, 69: 2 (jun.-dic. 2012), pp. 695-722.

“José Matías Quintana: un hombre entre dos tradiciones", en Quezada y Ortiz Yam (coords.), 2008, pp. 141-166.

"El proyecto educativo en Yucatán a fines del siglo xvinI y principios del xix: El Seminario y la Casa de Estudios", en Aguirre, 2013, pp. 399-420.

"El cabildo de Mérida de Yucatán y la experiencia de 18081810”, en Machuca Gallegos (coord.), 2014, pp. 257-280.

Machuca Gallegos, Laura (coord.)

Ayuntamientos y sociedad en el tránsito de la época colonial al siglo XIX. Reinos de Nueva España y Guatemala, México, Centro de Investigaciones y Estudios Superiores en Antropología Social, 2014.

Mantilla Gutiérrez, Jorge

"El pensamiento sanjuanista en el proceso de Independencia”, en Revista de la Universidad Autónoma de Yucatán, 229, segundo trimestre (2004), pp. 51-65.

Morange, Claude

"Opinion publique: ambivalence d'un concept (Espagne: 1750-1823)”, en Fernández Sebastián y Chassin (coords.), 2004, pp. 181-210.

Moreno Acevedo, Elda

"Pueblos y ayuntamientos. La construcción de la representación política en Yucatán, 1812-1821”, en Quezada y OrTiz YAM (coords.), 2008, pp. 59-82.

Piccato, Pablo

"Public Sphere in Latin America: A Map of the Historiography", en Social History, 35 (2) (mayo 2010), pp. 165-192. 
Quezada, Sergio e Inés Ortiz Yam (coords.)

Yucatán en la ruta del liberalismo mexicano, siglo XIX, Mérida, Universidad Autónoma de Yucatán, 2008.

Quintana, Matías

Clamores de la fidelidad americana contra la opresión, edición facsimilar por María del Carmen Ruiz Castañeda, México, Universidad Nacional Autónoma de México, 1986.

Rodríguez O., Jaime E.

"La naturaleza de la representación en Nueva España y México”, en Secuencia, 61 (ene.-abr. 2005), pp. 6-32.

Rojas, Rafael

La escritura de la independencia: el surgimiento de la opinión pública en México, México, Taurus, Centro de Investigación y Docencia Económicas, 2003.

Rubio Mañé, José Ignacio

"Juan (Emilio) Gustavo Nordingh de Witt, emisario del Ministro Miguel José de Azanza, al servicio de José Bonaparte, que llegó a Yucatán en el año de 1810”, en Boletín del Archivo General de la Nación, xv: 3 (jul.-ago.-sep. 1944), pp. 393-462.

"Juan (Emilio) Gustavo Nordingh de Witt, emisario del Ministro Miguel José de Azanza, al servicio de José Bonaparte, que llegó a Yucatán en el año de 1810”, en Boletín del Archivo General de la Nación, xv: 4 (oct.-nov.-dic. 1944), pp. 649-716. "Juan (Emilio) Gustavo Nordingh de Witt, emisario del Ministro Miguel José de Azanza, al servicio de José Bonaparte, que llegó a Yucatán en el año de 1810”, en Boletín del Archivo General de la Nación, xvi: 1 (ene.-feb.-mar. 1945), pp. 95-144. “Las ideas políticas en Yucatán. Año de 1810. Publica el proceso del padre de Andrés Quintana Roo; José Matías Quintana y del Campo, uno de los más entusiastas sanjuanistas", en Boletín del Archivo General de la Nación, xx: 2 (abr.-jun. 1949), pp. 261-276. 
"Los Sanjuanistas de Yucatán. Manuel Jiménez Solís, el padre Justis", en Boletín del Archivo General de la Nación, viII: 3-4 (jul.-dic. 1967), pp. 1213-1234.

"Los Sanjuanistas de Yucatán. Manuel Jiménez Solís, el padre Justis", en Boletín del Archivo General de la Nación, Ix: 1-2 (ene.-jun. 1968), pp. 195-243.

"Los Sanjuanistas de Yucatán. Manuel Jiménez Solís, el padre Justis", en Boletín del Archivo General de la Nación, Ix: 3-4 (jul.-dic. 1968), pp. 403-508.

"El gobernador, capitán general e intendente de Yucatán, mariscal don Manuel Artazo y Barral, y la jura de la constitución española en Mérida, el año de 1812", en Boletín del Archivo General de la Nación, Ix: 1-2 (1968), pp. 44-170.

"Los Sanjuanistas de Yucatán. Manuel Jiménez Solís, el padre Justis", en Boletín del Archivo General de la Nación, x: 1-2 (ene.-jun. 1969), pp. 129-253.

Sanmartín Barros, Israel, Patricia Calvo González y Eduardo REY TRISTÁN

Historia(s), Imagen(es) y Lenguaje(s) en América Latina y Europa, Santiago de Compostela, España, Universidad de Santiago de Compostela, 2012.

Serrano Ortega, José Antonio (coord.)

El sexenio absolutista, los últimos años insurgentes: Nueva España (1814-1820), Zamora, Mich., El Colegio de Michoacán, 2014.

Sierra O'Reilly, Justo

Los indios de Yucatán. Consideraciones históricas sobre la influencia del elemento indígena en la organización social del país, Mérida, Yuc., Universidad Autónoma de Yucatán, 1994, 2 volúmenes.

Torales Pacheco, María Cristina

Expresiones de la Ilustración en Yucatán, prólogo de José Ignacio Tellechea, México, Fundación E. Arocena, 2008. 
Torres Puga, Gabriel

Los últimos años de la Inquisición en Nueva España, México, Consejo Nacional para la Cultura y las Artes, Instituto Nacional de Antropología e Historia, Miguel Ángel Porrúa, 2005. Opinión pública y censura en Nueva España. Indicios de un silencio imposible, 1767-1794, México, El Colegio de México, 2010.

Uribe-Uran, Víctor M.

"The Birth of a Public Sphere in Late America During the Age of Revolution", en Comparative Studies in Society and History, 42: 2 (abr. 2000), pp. 425-457.

Zanolli Fabila, Betty Luisa

"La alborada del liberalismo yucateco. El primer ayuntamiento constitucional de Mérida Yucatán. 1812-1814”, tesis de maestría en historia, México, Universidad Nacional Autónoma de México, 1993. 
